\title{
Momentum Flux of Convective Gravity Waves Derived from an Offline Gravity Wave Parameterization. Part I: Spatiotemporal Variations at Source Level ${ }^{\circ}$
}

\author{
Min-Jee Kang And Hye-YeOng Chun \\ Department of Atmospheric Sciences, Yonsei University, Seoul, South Korea \\ YOUNG-HA KIM \\ Severe Storm Research Center, Ewha Womans University, Seoul, South Korea
}

(Manuscript received 18 February 2017, in final form 7 July 2017)

\begin{abstract}
Spatiotemporal variations in momentum flux spectra of convective gravity waves (CGWs) at the source level (cloud top), including nonlinear forcing effects, are examined based on calculations using an offline version of CGW parameterization and global reanalysis data for a period of 32 years (1979-2010). The cloud-top momentum flux (CTMF) is not solely proportional to the convective heating rate but is affected by the wave-filtering and resonance factor and background stability and temperature underlying the convection. Consequently, the primary peak of CTMF is in the winter hemisphere midlatitudes, associated with storm tracks, where a secondary peak of convective heating exists, whereas the secondary peak of CTMF appears in the summer hemisphere tropics and intertropical convergence zone (ITCZ), where the primary peak of convective heating exists. The magnitude of CTMF fluctuates largely with 1-yr and 1-day periods in major CTMF regions. At low latitudes and Pacific storm-track regions, a 6-month period is also significant, and the decadal cycle appears in the southern Andes. The equatorial eastern Pacific region exhibits a substantial interannual to decadal scale of variabilities. The correlation between convective heating and the CTMF is relatively lower in the equatorial region than in other regions. The CTMF in $10^{\circ} \mathrm{N}-10^{\circ} \mathrm{S}$ during the period of the pre-Concordiasi campaign approximately follows a lognormal distribution but with a slight underestimation in the tail of the probability density function. In Part II, the momentum flux and drag of CGW in the stratosphere will be examined.
\end{abstract}

\section{Introduction}

Atmospheric gravity waves (GWs) contribute significantly to the large-scale flow in the middle atmosphere through momentum deposition when they are filtered, broken, and diffused (Lindzen 1981; Matsuno 1982). The main sources of GWs in the troposphere are topography, convection, and the jet-front system. Convectively generated gravity waves (CGWs) have a broad spectrum and can thus transport their momentum through the mean flow throughout all seasons. It has

\footnotetext{
Supplemental information related to this paper is available at the Journals Online website: http://dx.doi.org/10.1175/JAS-D-170053.s1.
}

Corresponding author: Prof. Hye-Yeong Chun, chunhy@yonsei. ac.kr been demonstrated that the momentum deposition of the CGWs is important in driving the tropical variability such as the quasi-biennial oscillation (QBO) in the stratosphere and semiannual oscillation (SAO) in the mesosphere (Alexander and Holton 1997; Dunkerton 1997; Garcia et al. 1997; Baldwin et al. 2001). The CGWs also affect the Southern Hemisphere (SH) polar winter stratosphere. Choi and Chun (2013) showed that momentum forcing induced by CGW parameterization can effectively reduce excessive polar night jet and cold-pole biases of the Whole Atmosphere Community Climate Model (WACCM) in the SH, which are long-lasting problems in most general circulation models (GCMs).

Recently, with the aid of various observations, spatial and temporal variations in GW momentum flux (GWMF) or GW energy have been investigated (e.g., Tsuda et al. 2000; Baumgaertner and McDonald 2007; Hoffmann et al. 2013; Khaykin et al. 2015; Wright et al. 
2015; Sato et al. 2016). Tsuda et al. (2000) used global positioning system (GPS) meteorology data from April 1995 to February 1997 and retrieved GW energy to analyze seasonal and geographical variabilities in stratospheric GWs. Hoffmann et al. (2013) used 9-yr radiance measurement data from the Atmospheric Infrared Sounder (AIRS) to find the location and sources of stratospheric GW hot spots. Khaykin et al. (2015) used the Constellation Observing System for Meteorology, Ionosphere and Climate (COSMIC) GPS and Rayleigh temperature observations to construct 7-yr time series of GW potential energy in the Northern Hemisphere (NH) midlatitudes (near $44^{\circ} \mathrm{N}$ ) at $10-50 \mathrm{~km}$, which revealed the seasonal variation in $\mathrm{GW}$ activity. Wright et al. (2015) analyzed GW spectra observed from the High Resolution Dynamics Limb Sounder (HIRDLS) instrument at several altitudes in the stratosphere in 2007.

Generally, it is difficult to find long-term observational data covering the whole globe. Although global GWMF data can be obtained from satellite-retrieved temperature perturbations, measurement track and observational filter effects of the satellites often lead to difficulties in interpreting global GW features (Ern et al. 2011). In addition, it is rare that satellite instruments have both fine horizontal and vertical resolutions required for detecting small-scale GWs with horizontal (vertical) wavelengths of a few tens of kilometers (a few kilometers). For example, the lower limits of resolvable horizontal and vertical wavelengths of HIRDLS (Gille et al. 2008) are $100-200$ and $1-2 \mathrm{~km}$, respectively. High-resolution AIRS (Hoffmann et al. 2013) can capture GWs with a much higher horizontal resolution (approximately $13.5 \mathrm{~km}$ ). Recently, a measurement technique (three-dimensional analysis method using nadir-scanning instrument data) reported by Ern et al. (2017) showed a promising result in detecting a part of those small-scale GWs with less bias from the observing geometry than limb sounders (e.g., HIRDLS). However, both studies have a limitation in detecting GWs with vertical wavelengths shorter than approximately $15 \mathrm{~km}$.

High-resolution GCM and analysis data also have been utilized to investigate global structures of GWs (e.g., Watanabe et al. 2008; Liu et al. 2014; Preusse et al. 2014; Jewtoukoff et al. 2015). Watanabe et al. (2008) reported a high-resolution middle-atmosphere GCM with a T213 spectral horizontal resolution $\left(\sim 0.56^{\circ}\right)$ that explicitly simulates GWs generated by various sources. Liu et al. (2014) presented GWs from the surface to the lower thermosphere simulated with a horizontal resolution of $\sim 0.25^{\circ}$ using WACCM. However, GCMs with a horizontal resolution of $\sim 25 \mathrm{~km}$ cannot explicitly resolve GWs with wavelengths shorter than $\sim 200 \mathrm{~km}$ (Preusse et al. 2014). In addition, a high-resolution GCM simulation for a long period, which is enough to detect climate signals (more than $\sim 10$ years), has not been reported so far because it consumes a large amount of computational resources.

In this study, we calculate the CGW momentum flux for a long period (32 years) with fine temporal resolution (1 hourly) using a physically based and sourcedependent parameterization and global reanalysis data. The parameterization used here considers small-scale CGWs generated by single convective cells, which have horizontal wavelengths of up to about $100 \mathrm{~km}$, as will be seen later. The spatiotemporal variations in the sourcelevel (cloud top) momentum flux of CGWs are examined for the first time. There have been increased efforts to understand the relationship between GWs and other atmospheric phenomena. For example, Sato et al. (2016) and Tsuchiya et al. (2016) investigated the relationship of GW activity with El Niño-Southern Oscillation (ENSO) and the Madden-Julian oscillation (MJO), respectively, using temperature variances at an altitude of $z=39 \mathrm{~km}$ from 8-yr AIRS data. The dataset created in our study [Part I and M.-J. Kang et al. (2017, unpublished manuscript, hereafter Part II)] can be utilized to study such a relationship, as the results provide the full vertical information of GW quantities above the tropospheric convection associated with ENSO and the MJO. The CGW momentum flux at the cloud-top level is investigated in this paper, and the stratospheric aspects of the CGWs will be presented in Part II. The remainder of this paper is organized as follows. The background and methodology of the parameterization and reanalysis data used in this study are described in section 2. In section 3, spatiotemporal variations in the cloud-top CGW momentum flux are examined. The intermittency in the momentum flux is assessed and compared with previous studies in section 4 , followed by a summary and discussion in section 5 .

\section{CGW parameterization and reanalysis data}

\section{a. Background}

The CGW parameterization used in this study is based on Song and Chun (2005, hereafter SC05), who derived an analytic solution of convective heating-induced GW momentum flux at cloud top as a function of phase velocity. This analytic solution considers several important aspects of CGWs revealed in previous numerical and theoretical studies. It considers the low-level shear, which is one of the major factors determining the asymmetric phase speed spectrum of CGWs (Beres et al. 2002). The solution also includes the resonance effect in vertical wave modes by the depth and height of convective heating (Salby and Garcia 1987; SC05). The SC05 parameterization was 
validated using satellite-derived temperature variances from Microwave Limb Sounder observations (Choi et al. 2009) and was further validated and updated by Choi and Chun (2011, hereafter CC11) using three-dimensional ideal and real-case mesoscale simulations that explicitly resolve CGWs. It was shown in CC11 that the cloud-top momentum flux (CTMF) spectrum obtained from the parameterization well matches that from the simulations for the ideal and real-case storms, with an updated representation of convection moving speed in the parameterization. The CC11 parameterization was also compared with AIRS observations and showed good agreements as well (Choi et al. 2012). Recently, Trinh et al. (2016) and Kalisch et al. (2016) showed that offline calculation of the CC11 parameterization using various spatiotemporal scales of convective sources can reproduce the GWMF observed by limb-sounding satellites in the tropical stratosphere.

While the diabatic heating in convection has been considered as a source of waves in CGW parameterizations (Beres et al. 2004; SC05) several numerical studies also have demonstrated the importance of nonlinear forcing in the CGW generation mechanism (e.g., Lane et al. 2001; Song et al. 2003). Lane et al. (2001) showed that nonlinear forcing, possibly associated with the oscillating convective updraft, has a larger magnitude than diabatic forcing. Song et al. (2003) demonstrated that the effective forcing that takes into account a wave propagation condition in the spectral domain actually generates GWs that reach the stratosphere, and the effective nonlinear forcing and effective diabatic forcing are comparable and largely out of phase with each other. Therefore, both forcing mechanisms should be considered in the parameterization in order to avoid overestimation of the CTMF of CGWs when a single source (e.g., diabatic heating alone) is considered. It is, however, not straightforward to formulate CTMF including both diabatic and nonlinear forcing in the parameterization because of the complexity of the nonlinear forcing structure. Chun et al. (2008) proposed a way to incorporate the effect of nonlinear forcing into the CTMF formulation based on the nonlinearity of the thermally induced internal GWs (Lin and Chun 1991), and we adapt this methodology in the present study.

\section{b. Formulation of the CTMF spectrum}

The formulation of the CTMF spectrum used in this study is as follows:

$$
\begin{aligned}
M_{\mathrm{ct}}(c, \varphi)= & \operatorname{sgn}\left[c-U_{\mathrm{ct}}(\varphi)\right] \rho_{\mathrm{ct}} \frac{2(2 \pi)^{3}}{A_{h} L_{t}}\left(\frac{g}{c_{p} T_{q} N_{q}^{2}}\right)^{2} \\
& \times \frac{N_{\mathrm{ct}}|X|^{2}}{\left|c-U_{\mathrm{ct}}(\varphi)\right|} \Theta(c, \varphi) F(\mu) .
\end{aligned}
$$

Equation (1) is the same as the CTMF formulation in SC05 and CC11 except that the term $F(\mu)$, which represents the nonlinear forcing effect, is included. Here, $c$ is the ground-based phase speed, and $\varphi\left(0^{\circ} \leq \varphi<180^{\circ}\right)$ is the wave propagation direction; $U_{\mathrm{ct}}(\varphi)$ is the basic-state wind at cloud top projected on the direction of $\varphi ; \rho_{\mathrm{ct}}$ and $N_{\text {ct }}$ are the air density and static stability at the cloud top, respectively; $T_{q}$ and $N_{q}$ are the air temperature and static stability averaged from cloud top to bottom, respectively; $A_{h}$ and $L_{t}$ are the horizontal area and the time scale for averaging the momentum flux, which are $\pi(120)^{2} \mathrm{~km}^{2}$ and $20 \mathrm{~min}$, respectively; $g$ is the gravitational acceleration; and $c_{p}$ is the specific heat of air at constant pressure. Following CC11, two azimuthal directions of wave propagation, $\varphi=45^{\circ}$ and $135^{\circ}$, are considered in the CTMF calculation. Because both positive and negative phase speeds are considered in each direction, the waves propagate to four directions $\left(45^{\circ}, 135^{\circ}, 225^{\circ}\right.$, and $\left.315^{\circ}\right)$.

The spectral shape of CTMF in Eq. (1) is determined by two factors: (i) $N_{\mathrm{ct}}|X|^{2} /\left|c-U_{\mathrm{ct}}(\varphi)\right|$, which is referred to as the wave-filtering and resonance factor (WFRF) by SC05 and CC11, and (ii) $\Theta(c, \varphi)$, the convective source spectrum. Here, $|X|$ is a complicated function of the basic-state wind and stability and convective-forcing height and depth, which can be found in appendix A of SC05. The WFRF represents both the wave filtering by critical levels in the source layer and the resonance between vertical harmonics of the convective source and natural wave modes with vertical wavenumbers given by the dispersion relation. The methodology to determine the vertical profile of convective forcing is given in the appendix. The convective source spectrum is expressed as

$$
\Theta(c, \varphi)=q_{0}^{2}\left(\frac{\delta_{h} \delta_{t}}{32 \pi^{3 / 2}}\right)^{2} \frac{1}{1+\left[c-c_{q h}(\varphi)\right]^{2} / c_{0}^{2}},
$$

which is derived analytically for diabatic forcing by a moving convection with a Gaussian temporal and horizontal distribution (SC05). Here, $q_{0}=H_{\max } c_{f} c_{p}$, where $H_{\text {max }}$ is the column-maximum deep convective heating rate, and $c_{f}$ is the conversion factor required to obtain a reasonable magnitude of $\mathrm{CTMF} ; c_{q h}(\varphi)$ is the moving speed of convection projected on the direction of $\varphi$, which, following CC11, is determined as the basic-state wind velocity averaged below $700 \mathrm{hPa}$; and $c_{0}$ is defined as $\delta_{h} / \delta_{t}$, where $\delta_{h}$ and $\delta_{t}$ are spatial and time scales of convective forcing, respectively. In this study, $\delta_{h}\left(\delta_{t}\right)$ is set to $5 \mathrm{~km}$ ( $20 \mathrm{~min}$ ) following the previous studies (Song et al. 2007; CC11). In Trinh et al. (2016), a combination of different scales of $\delta_{h}$ and $\delta_{t}$ is considered, including $\delta_{h}$ larger than $200 \mathrm{~km}$ and $\delta_{t}$ longer than $1 \mathrm{~h}$, to represent 
the observed GWs from HIRDLS with long horizontal and vertical wavelengths detected from satellite instruments. In the present study, we consider a single Gaussian-type cloud with $\delta_{h}=5 \mathrm{~km}$ and $\delta_{t}=20 \mathrm{~min}$, because we are interested mainly in CGWs generated by local convective clouds, which are represented best by sub-grid-scale convective clouds in GCMs, and they have to be parameterized in GCMs.

We set the conversion factor $c_{f}$ to 565 , taking into consideration the GW momentum flux estimation from the superpressure balloon observation in the tropics. Jewtoukoff et al. (2013) estimated the GW momentum flux as $3.9-5.4 \mathrm{mPa}$ from the superpressure balloon observation in the deep tropics at $\sim 50 \mathrm{hPa}$ during 8 February-11 May 2010. Considering that other sources of GWs (e.g., topography and instabilities) are partly included in the observation, the observed GWs could be larger than those by the current CGW parameterization. With $c_{f}=565$, the parameterized CGW momentum flux averaged over $10^{\circ} \mathrm{N}-10^{\circ} \mathrm{S}$ at $50 \mathrm{hPa}$ for the same period with the observation was about $3 \mathrm{mPa}$, when the Lindzen-type saturation scheme (Lindzen 1981) was used, assuming columnar vertical propagation of waves above the cloud top.

The nonlinear forcing effect on the CTMF is considered in Eq. (1) by the scale factor $F(\mu)$ :

$$
F(\mu)=1 /\left(1+a \mu^{b}\right),
$$

where $a=0.48792$ and $b=1.64896$ (Chun et al. 2008), and $\mu$ is the nonlinearity factor for thermally induced GWs defined by Lin and Chun (1991) and Chun and Baik (1998):

$$
\mu=\frac{g Q_{0} L}{c_{p} T_{0} N_{c} U_{c}^{2}} .
$$

Here, $Q_{0}$ is the magnitude of convective heating; $T_{0}$ refers to the reference temperature; and $L, N_{c}$, and $U_{c}$ are the characteristic scales of horizontal length, static stability, and basic-state wind relative to the convection, respectively. To calculate the nonlinearity factor using global reanalysis data, $Q_{0}=q_{0}, L=\delta_{h}, T_{0}=T_{q}$, and $N_{c}=N_{q}$ are applied. Equation (4) indicates that as the wind flow into the convection and the static-stability decrease and as the magnitude and scale of heating increase, the nonlinearity factor increases. This relationship has also been reported in several previous studies (e.g., Smith and Lin 1982; Lin and Smith 1986; Lin and Chun 1991). The scale factor $F(\mu)$ decreases as $\mu$ increases [Eq. (3)].

\section{c. Reanalysis data}

The National Centers for Environmental Prediction (NCEP) Climate Forecast System Reanalysis (CFSR;
Saha et al. 2010) data are used for the present offline calculation of CTMF. CFSR used an atmosphere-oceanland surface-sea ice coupled model with relatively fine resolution (T382, L64). The model uses a deep convective parameterization of simplified Arakawa-Schubert cumulus convection (Pan and Wu 1995; Hong and Pan 1996), with cumulus momentum mixing (Saha et al. 2010). It has been shown that temporal variabilities in tropical precipitation of CFSR are better than other reanalysis data (Wang et al. 2012; Kim and Alexander 2013). Note that CFSR provides the deep and shallow convective heating rate separately, and we only use the deep convective heating rate to focus on the CGWs generated from the deep convection. The variables used in this study are the horizontal wind, temperature, geopotential height, deep convective heating rate, convective cloudtop pressure, and convective cloud-bottom pressure at $1^{\circ}$ longitude by $1^{\circ}$ latitude resolution. The data have 37 pressure levels, with the top at $1 \mathrm{hPa}$. We use the forecast fields with a 1-h data interval, considering the rapidly changing nature of convective clouds. The calculation period is 32 years from January 1979 to December 2010.

\section{Spatiotemporal variations in CTMF}

\section{a. Global distribution}

Figure 1 shows the 32-yr (1979-2010) averaged column-maximum deep convective heating rate $(\mathrm{DCH})$, convective cloud-top height $z_{\mathrm{ct}}$, and magnitude of CTMF in January (Fig. 1a) and July (Fig. 1b). Note that $\mathrm{DCH}$ and CTMF are averaged including zero values with no convection cases, while $z_{\mathrm{ct}}$ is averaged only when convection exists. The zonal mean of each variable is denoted on the right side of each panel. The red line (black line) on the bottom-left panel of Fig. 1 is the zonalmean CTMF excluding (including) the nonlinear forcing effect [i.e., CTMF without (with) $F(\mu)$ in Eq. (1)]. In January, strong convective heating is primarily concentrated in the intertropical convergence zone (ITCZ) around $5^{\circ} \mathrm{N}$ and the continental areas in the summer hemisphere tropics (top-left panel of Fig. 1a). The secondary peak exists in the winter hemisphere storm-track regions of $30^{\circ}-50^{\circ} \mathrm{N}, 120^{\circ} \mathrm{E}-150^{\circ} \mathrm{W}$ (Pacific storm track) and $30^{\circ}-50^{\circ} \mathrm{N}, 20^{\circ}-80^{\circ} \mathrm{W}$ (Atlantic storm track). High clouds are located in the tropics and summer monsoon regions $\left(10^{\circ} \mathrm{N}-30^{\circ} \mathrm{S}\right)$, where $\mathrm{DCH}$ is large, especially over continents.

The local maxima of CTMF (bottom-left panel of Fig. 1a) are generally matched with DCH. However, in CTMF, the primary peak is located in the winter hemisphere storm-track regions rather than tropical regions, where the primary peak of DCH exists. This is because 


\section{(a) January}
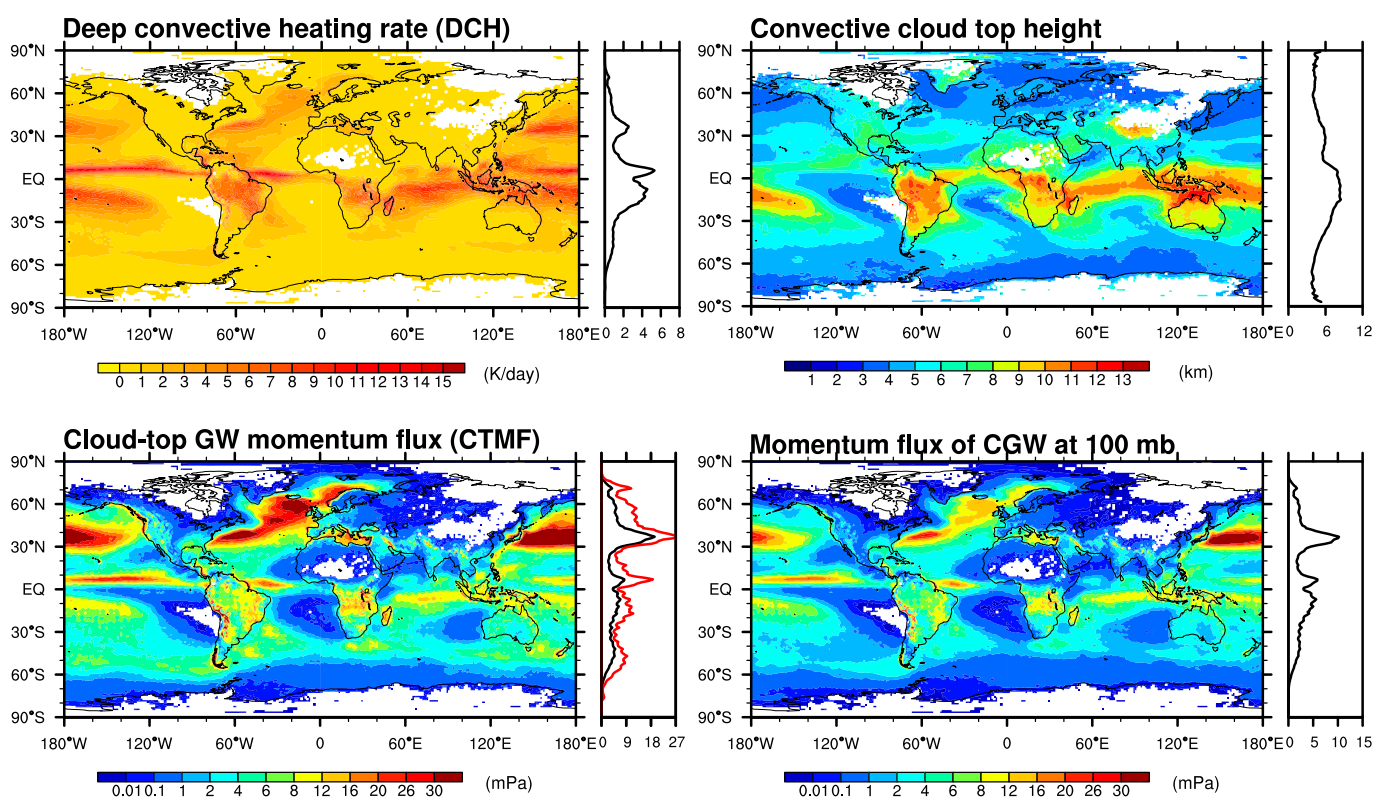

(b) July
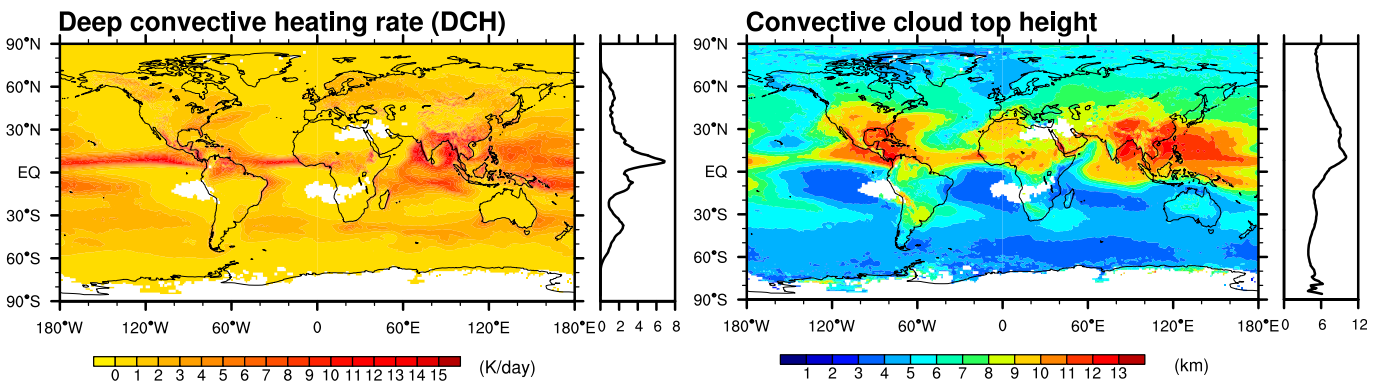

Cloud-top GW momentum flux (CTMF)

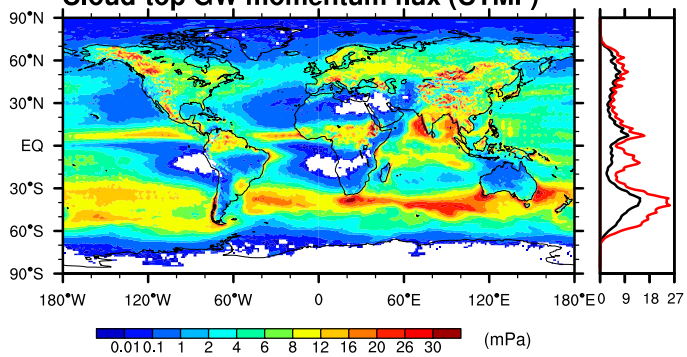

Momentum flux of CGW at $100 \mathrm{mb}$

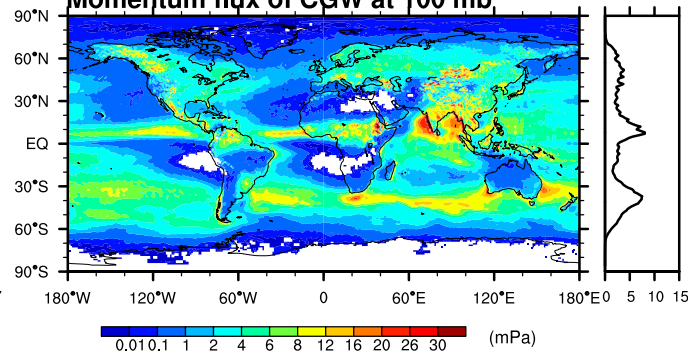

FIG. 1. (top left) Global distributions of column-maximum deep convective heating rate, (top right) estimated convective cloud-top height, (bottom left) absolute CTMF, and (bottom right) GWMF of convective gravity waves at $100 \mathrm{mb}(1 \mathrm{mb}=1 \mathrm{hPa})$ in (a) January and (b) July averaged from 1979 to 2010 . The zonal-mean values are plotted to the right of each panel. The red line on the right side of the bottom-left panel is the zonal mean of CTMF when the nonlinear forcing effect is not included (diabatic forcing only).

the CTMF is not solely proportional to the magnitude of convective heating but to other factors included in Eq. (1) as well. First, the spectral combination between the convective source and WFRF is significantly different between the tropics and midlatitudes. The WFRF spectrum generally coincides with the convective source spectrum in the midlatitude storm-track regions, while it does not in the tropics. The coincidence of the two spectra leads to the large CTMF in the midlatitudes. Second, background conditions underlying deep convection are favorable for 
exciting waves of larger amplitudes in the winter midlatitudes; stability $N_{q}$ and air temperature $T_{q}$ are smaller in the midlatitudes, leading to a larger CTMF in the midlatitudes than in the tropics. In Eq. (1), the term $\left[g /\left(c_{p} T_{q} N_{q}^{2}\right)\right]^{2}$ is $0.18(0.08) \mathrm{kg}^{2} \mathrm{~J}^{-2} \mathrm{~m}^{2}$ over $30^{\circ}-50^{\circ} \mathrm{N}$ $\left(0^{\circ}-20^{\circ} \mathrm{S}\right)$. This difference largely stems from $N_{q}$, the static stability averaged from cloud top to bottom. In January, for example, the cloud-bottom and cloud-top heights in $30^{\circ}-50^{\circ} \mathrm{N}$ are 1.92 and $5.26 \mathrm{~km}$, respectively, while those in $0^{\circ}-20^{\circ} \mathrm{S}$ are 1.25 and $8.15 \mathrm{~km}$. The $N_{q}$ averaged in the cloud region is smaller in $30^{\circ}-50^{\circ} \mathrm{N}$ than in $0^{\circ}-20^{\circ} \mathrm{S}$. This is because the static stability in the lower and middle troposphere $(0.98-5.57 \mathrm{~km})$ in the winter hemisphere midlatitude regions is lower than in the tropical regions, while it is opposite in the upper troposphere (not shown). Third, a different air density $\left(0.76 \mathrm{~kg} \mathrm{~m}^{-3}\right.$ in $30^{\circ}-50^{\circ} \mathrm{N}$ and $0.53 \mathrm{~kg} \mathrm{~m}^{-3}$ in $0^{\circ}-20^{\circ} \mathrm{S}$ ) due to the different cloud-top altitudes (Fig. 1a) also contributes to the relatively large CTMF in midlatitudes. Last, the nonlinear forcing effect can be partly responsible for the larger CTMF in the midlatitudes than in the tropics. As shown in Eqs. (3) and (4), CTMF is reduced more when the nonlinear factor is larger. In the winter midlatitudes, $U_{c}$ in Eq. (4) is larger than that in the tropics, and this leads to a smaller $\mu$, regardless of the relatively smaller value of $N_{c}\left(=N_{q}\right)$ than in the tropics. In July, the reduction of momentum flux in the summer hemisphere tropics by including the nonlinear forcing effect is much less than in January.

To exclude the effect of the spatially inhomogeneous cloud-top height, the CGW momentum flux at $100 \mathrm{hPa}$ is calculated using the Lindzen-type wave saturation scheme with columnar wave propagation (bottom-right panel of Fig. 1a). The spatial structure of the 100-hPa momentum flux is generally similar to that of CTMF, although the magnitude is reduced from that at the cloud top, particularly in the winter hemisphere storm-track regions. This is because wave dissipation by the background wind occurs strongly in the upper troposphere and lower stratosphere (UTLS) of the midlatitudes.

In July (Fig. 1b), the spatial distributions are similar to those in January (Fig. 1a), considering the hemispheric change in convective activities. DCH is large in the ITCZ and the summer monsoon regions (American monsoon and Asian monsoon), ranging from $10^{\circ} \mathrm{S}$ to $30^{\circ} \mathrm{N}$, where the convective cloud top is high. The maximum CTMF occurs in the winter hemisphere midlatitudes $\left(30^{\circ}-50^{\circ} \mathrm{S}\right)$, and a secondary peak exists over the summer hemisphere tropical region and ITCZ $\left(0^{\circ}-20^{\circ} \mathrm{N}\right)$, as observed in January. However, the difference in CTMF between the winter storm-track regions and summer tropics is less in July, and the momentum flux at $100 \mathrm{hPa}$ in July in the summer hemisphere tropics is comparable to that in the winter hemisphere storm-track region $(\sim 5.5 \mathrm{mPa})$. This is because of strong convection with a large magnitude of $\mathrm{DCH}$ in the Asian summer monsoon region (Fig. 1b), and the reduction rate after including the nonlinear forcing effect in the tropics is smaller than in January. Note that the magnitude of the CTMF and the resulting latitudinal difference in the CTMF are sensitive, in particular, to the depth of the convective forcing. The way to estimate the vertical profile of the convective forcing from the given reanalysis data is described in the appendix.

Figure 2 shows the phase speed spectra of the zonalmean zonal CTMF averaged from $30^{\circ}$ to $50^{\circ}$ of the winter hemisphere and from $0^{\circ}$ to $20^{\circ}$ of the summer hemisphere, in which a large magnitude of CTMF appears in Fig. 1. The spectra of the convective source and WFRF are also plotted in Fig. 2. The convective source spectrum has its peak following the moving speed of convection, as shown in Eq. (2). Accordingly, in January (Fig. 2a), spectral peaks of the convective source exist at $c=12 \mathrm{~m} \mathrm{~s}^{-1}$ in $30^{\circ}-50^{\circ} \mathrm{N}$ and near $c=0$ in $0^{\circ}-20^{\circ} \mathrm{S}$. The convective source spectrum in July is very similar $(c=$ $12 \mathrm{~m} \mathrm{~s}^{-1}$ in $30^{\circ} \mathrm{N}-50^{\circ} \mathrm{S}$, and $c=-2 \mathrm{~m} \mathrm{~s}^{-1}$ in $\left.0^{\circ}-20^{\circ} \mathrm{N}\right)$, although its magnitude in $0^{\circ}-20^{\circ} \mathrm{N}$ is slightly larger than that in $0^{\circ}-20^{\circ} \mathrm{S}$ in January. The spectral peaks of WFRF, which is somewhat complicated, as mentioned in section $2 \mathrm{~b}$, are at $c=2$ and $22 \mathrm{~m} \mathrm{~s}^{-1}$ in $30^{\circ}-50^{\circ} \mathrm{N}$, while they are at $c=-32,-12,10$, and $30 \mathrm{~m} \mathrm{~s}^{-1}$ in $0^{\circ}-20^{\circ} \mathrm{S}$ in January. The combination of convective source and WFRF spectra leads to large values in the phase speed range between 10 and $30 \mathrm{~m} \mathrm{~s}^{-1}$ in $30^{\circ}-50^{\circ}$ in the winter hemisphere, where both the convective source and WFRF spectra are large. In $0^{\circ}-20^{\circ} \mathrm{N}$ in January and $0^{\circ}-20^{\circ} \mathrm{S}$ in July, however, the peak of each spectrum is not matched well; WFRF is nearly minimum at $c=0$, where the convective source is maximal. Consequently, the CTMF spectrum is relatively large in January (July) between $30^{\circ}$ and $50^{\circ} \mathrm{N}\left(30^{\circ}\right.$ and $\left.50^{\circ} \mathrm{S}\right)$ and is small between $0^{\circ}$ and $20^{\circ} \mathrm{S}$ (between $0^{\circ}$ and $20^{\circ} \mathrm{N}$ ). Note that the spectral shape of CTMF varies significantly in space and time, which is not shown in the 32-yr averaged spectra of Fig. 2.

Figure 3 shows the phase speed spectrum of the zonalmean zonal (top) and meridional (bottom) CTMF in January (left) and July (right). The zonal-mean zonal winds (not shown) in the troposphere are strong westerly in the midlatitudes and weak easterly in the tropics, and correspondingly, the locations of zero zonal CTMF are at positive (negative) phase speeds in the midlatitudes (tropics). Note that the sign of the momentum flux is determined by the sign of $c-U$ for upward-propagating GWs. In the winter hemisphere midlatitudes, $30^{\circ}-60^{\circ} \mathrm{N}$ $\left(30^{\circ}-60^{\circ} \mathrm{S}\right)$ in January (July), the CTMF has phase speeds ranging from about 60 to $-60 \mathrm{~m} \mathrm{~s}^{-1}$, and its peak is larger for the westward CTMF than for the eastward CTMF. On the other hand, in the summer hemisphere tropics, $0^{\circ}-20^{\circ} \mathrm{S}$ 
(a) January

Convective source \& WFRF
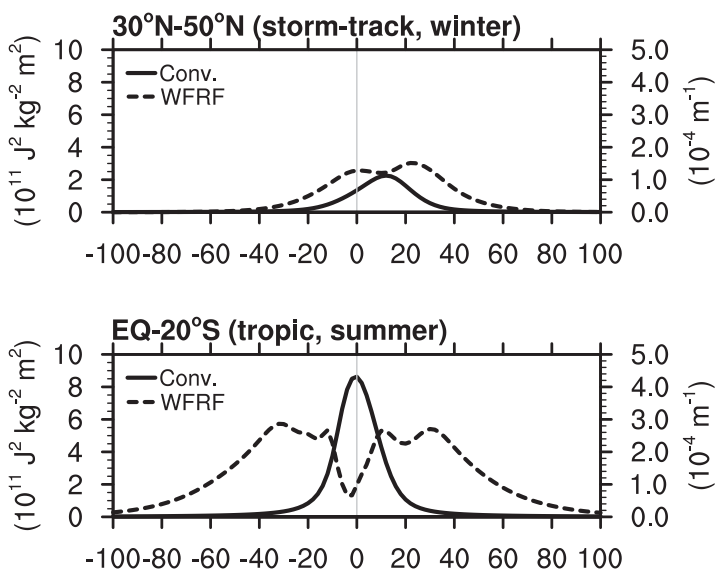

Phase speed $(\mathrm{m} / \mathrm{s})$
CTMF
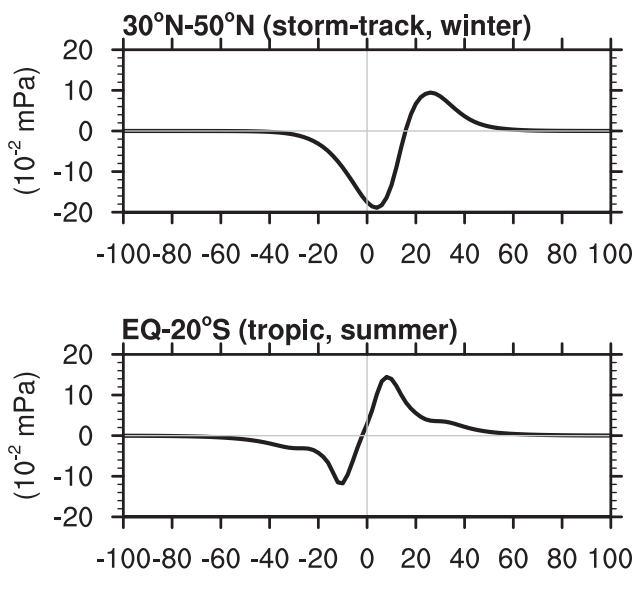

Phase speed $(\mathrm{m} / \mathrm{s})$

\section{(b) July}

Convective source \& WFRF
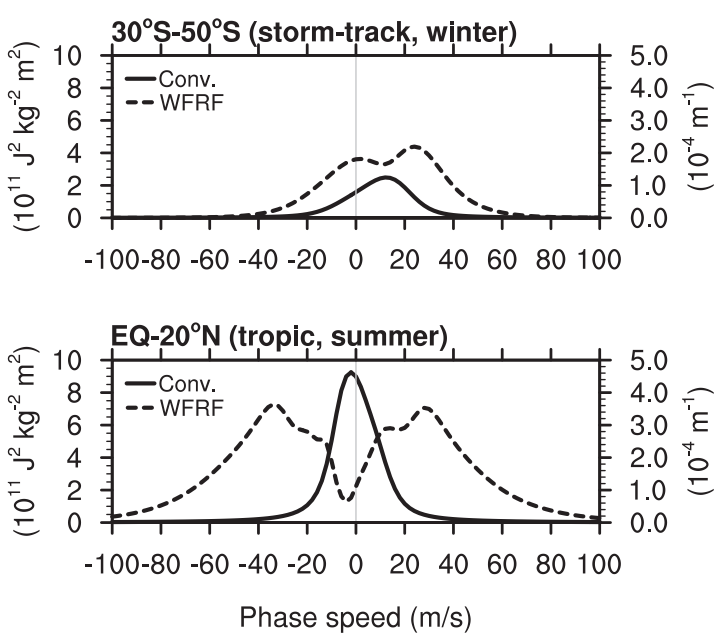

\section{CTMF}
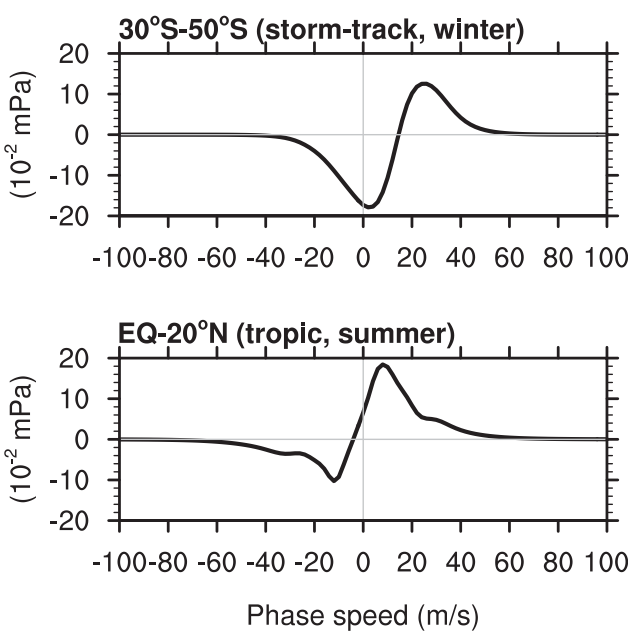

FIG. 2. The 32-yr (1979-2010) averaged zonal (left) convective source spectra (solid line) and WFRF spectra (dashed line) and (right) CTMF spectra averaged over latitudes of winter hemisphere storm-track region and summer hemisphere tropical region in (a) January and (b) July.

$\left(0^{\circ}-20^{\circ} \mathrm{N}\right)$, the CTMF has a much broader spectrum $\left( \pm 100 \mathrm{~m} \mathrm{~s}^{-1}\right)$ than in the winter hemisphere midlatitudes, and the eastward CTMF is larger than the westward CTMF. The broader CTMF spectra in the summer hemisphere tropics than in the midlatitudes is due to a wide spectrum of WFRF associated with deep convective clouds in the tropics, leading to spectral peaks at high phase speeds (SC05). A relatively strong zonal CTMF spectrum appears in $30^{\circ}-60^{\circ} \mathrm{N}$ in July, compared with in $30^{\circ}-60^{\circ} \mathrm{S}$ in January. This is likely because the larger continental areas in the NH midlatitudes result in more active terraininduced convection than in the $\mathrm{SH}$ midlatitudes.
The meridional CTMF spectra are nearly symmetric with respect to $c=0$, as the meridional wind is relatively weak. At certain latitudes $\left(30^{\circ}-40^{\circ} \mathrm{N}\right.$ and $40^{\circ}-60^{\circ} \mathrm{S}$ in January; $30^{\circ}-60^{\circ} \mathrm{S}$ in July), however, the meridional CTMF spectra show alternating positive and negative values. This is related somewhat to the azimuthal angles $\left(45^{\circ}\right.$ and $\left.135^{\circ}\right)$ of wave propagation that are assigned in the parameterization, based on the validation of the parameterization against mesoscale simulations of convective GWs (Choi and Chun 2011). When there is a strong horizontal wind, as in the winter midlatitudes, the projected wind in the meridional direction becomes 


\section{CTMF spectrum (1979-2010)}
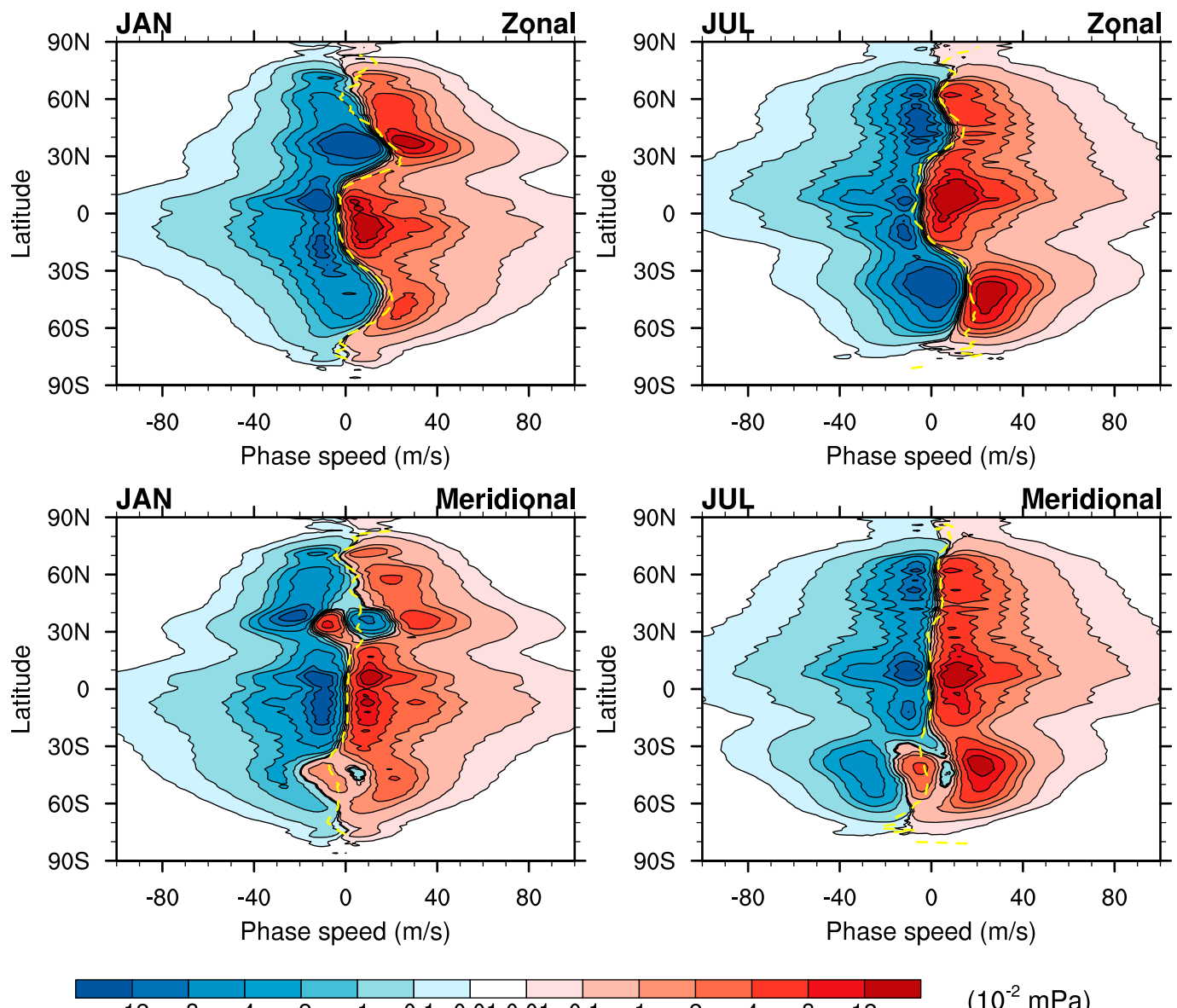

$\begin{array}{llllllllllllll}-12 & -8 & -4 & -2 & -1 & -0.1 & -0.01 & 0.01 & 0.1 & 1 & 2 & 4 & 8 & 12\end{array}$

$\left(10^{-2} \mathrm{mPa}\right)$

FIG. 3. Latitudinal distributions of 32-yr (1979-2010) averaged (top) zonal-mean zonal and (bottom) meridional CTMF spectra in (left) January and (right) July. The zonal-mean zonal and meridional wind averaged over same period are also plotted (yellow dashed line).

large in the given azimuthal angles, resulting in the zero lines of meridional CTMF at relatively high phase speeds. The magnitude of the meridional CTMF spectrum is comparable to the zonal counterpart, and the latitudinal variations in the spectral width appear in the meridional spectrum as well.

In Figs. 2 and 3, CTMF in the winter hemisphere stormtrack region show relatively wide phase speed spectra, along with dominant westward momentum flux with a nonnegligible amount of eastward momentum flux. The magnitudes of northward and southward momentum fluxes are comparable with each other. This feature is consistent with high-resolution mesoscale simulations of idealized moist baroclinic jet-front systems with convective instability by Wei et al. (2016), for the moderate to strong moist run [see Figs. 2 and 3 of Wei et al. (2016)]. This implies that CGWs in the storm-track regions may be related to the convective clouds associated with jetfront systems, and this suggests that any parameterization of GWs associated with a jet-front system should include only dry mode modified by moist convection to prevent a double count of convectively generated gravity waves, as also mentioned by Wei et al. (2016).

Figure 4 is the power spectrum of CTMF with respect to the horizontal wavenumber $k_{h}$ and vertical wavenumber $m$ in five latitudinal bands $\left(45^{\circ}-75^{\circ} \mathrm{N}, 15^{\circ}-45^{\circ} \mathrm{N}\right.$, $15^{\circ} \mathrm{N}-15^{\circ} \mathrm{S}, 15^{\circ}-45^{\circ} \mathrm{S}$, and $45^{\circ}-75^{\circ} \mathrm{S}$ ) in January (Fig. 4a) and July (Fig. 4b). Strong powers exist at horizontal wavelengths $\lambda_{h}$ from 8 to $100 \mathrm{~km}$ and vertical wavelengths $\lambda_{z}$ from 1 to $40 \mathrm{~km}$, with latitudinal dependence. At $45^{\circ}-75^{\circ} \mathrm{N}$ in January (Fig. 4a), where the CTMF peaks exist in the northern part of the North Atlantic and Norwegian Sea (Fig. 1a), the CTMF is concentrated over relatively short wavelengths: $\lambda_{h}$ of $8-40 \mathrm{~km}$ and $\lambda_{z}$ of 
(a) CTMF $k_{h}-$ m spectrum (JAN)
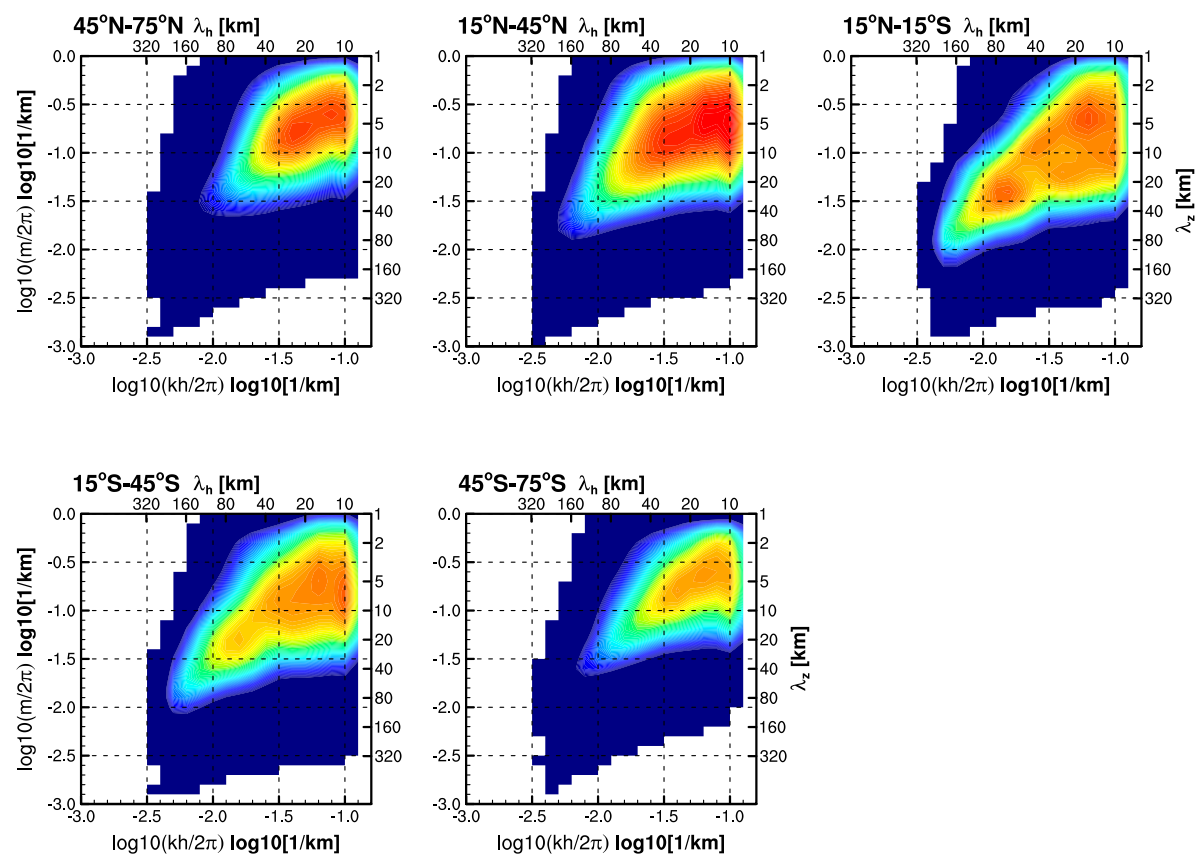

$\begin{array}{llllllll}-7 & -6.5 & -6 & -5.5 & -5 & -4.5 & -4 & -3.5\end{array}$

GW mom. flux / grid point log10[Pa $\left.\mathbf{~ k m}^{2}\right]$

(b) CTMF $k_{h}-$ m spectrum (JUL)
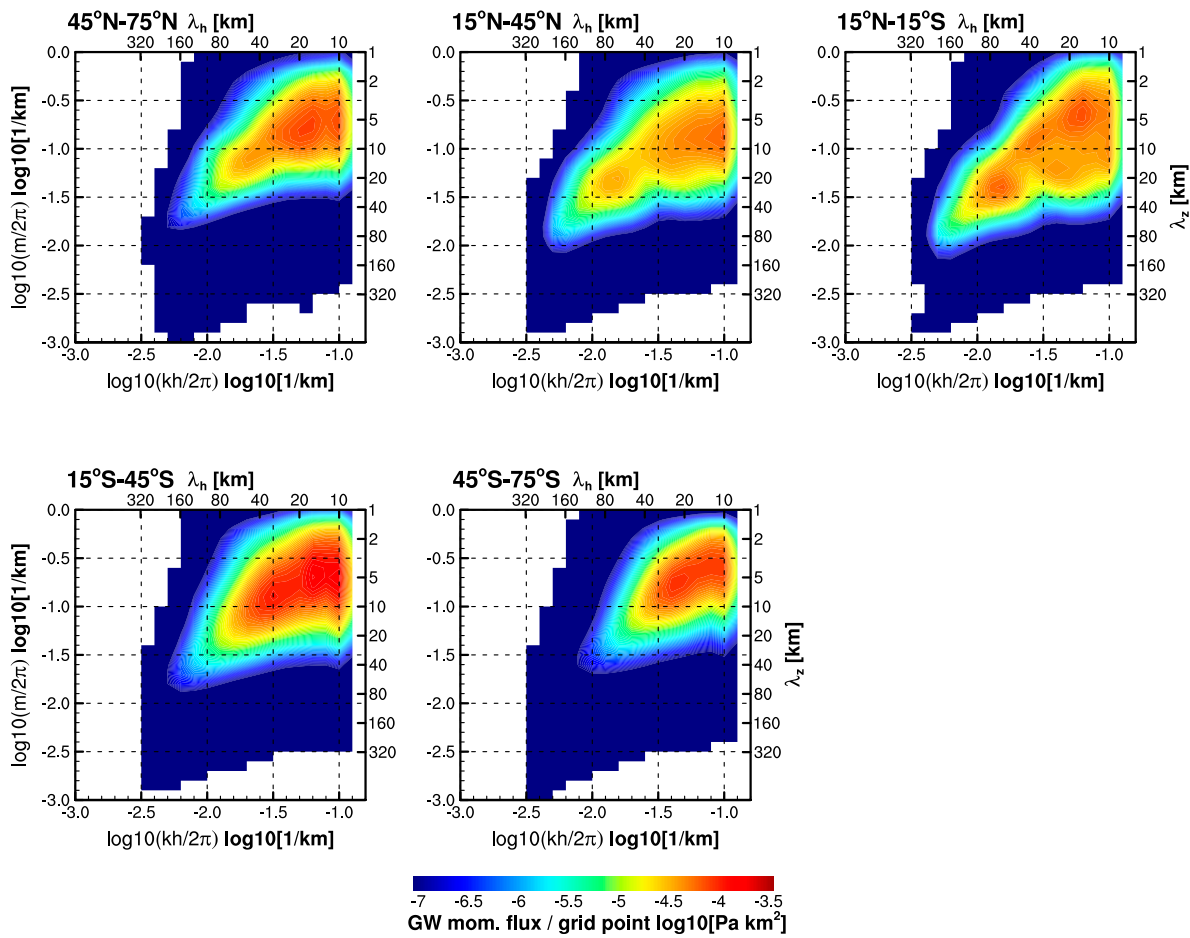

FIG. 4. The 32-yr (1979-2010) averaged CTMF magnitude with respect to horizontal wavelength ( $x$ axis) and vertical wavelength ( $y$ axis) averaged over (top left to bottom center) $45^{\circ}-75^{\circ} \mathrm{N}, 15^{\circ}-45^{\circ} \mathrm{N}$, $15^{\circ} \mathrm{N}-15^{\circ} \mathrm{S}, 15^{\circ}-45^{\circ} \mathrm{S}, 45^{\circ}-75^{\circ} \mathrm{S}$ in (a) January and (b) July. 
2-10 km. The spectral power in the latitude band of $15^{\circ}-45^{\circ} \mathrm{N}$, which includes the Pacific and Atlantic stormtrack regions, is the strongest among the five bands, as expected based on Fig. 1a, concentrating at $\lambda_{h}$ and $\lambda_{z}$ ranging between 8 and $80 \mathrm{~km}$ and between 2 and $20 \mathrm{~km}$, respectively. In the tropical region $\left(15^{\circ} \mathrm{N}-15^{\circ} \mathrm{S}\right)$, one additional peak appears in the large wavelength ranges $\left(\lambda_{h}\right.$ between 60 and $140 \mathrm{~km}$, and $\lambda_{z}$ between 20 and $40 \mathrm{~km}$ ), and this is due to the resonance between GWs with large vertical wavelength forced by deep convection in the tropical region and natural wave modes. Notable spectral powers of the CTMF extend to $\lambda_{h}$ and $\lambda_{z}$ of 200 and $100 \mathrm{~km}$, respectively, in the tropical region. GWs with long vertical wavelengths can propagate into the stratosphere without significant filtering, which is responsible for the lesser reduction in the momentum flux at $100 \mathrm{hPa}$ in the tropical region from the CTMF, compared with other regions (Fig. 1a). The latitudinal bands of $15^{\circ} \mathrm{N}-15^{\circ} \mathrm{S}$ and $15^{\circ}-45^{\circ} \mathrm{S}$ contain highcloud regions (Fig. 1a), leading to CGWs with relatively longer vertical wavelengths (Fig. 4a). The spectral power over $45^{\circ}-75^{\circ} \mathrm{S}$ is the weakest among the powers in the five bands, being concentrated over a relatively short wavelength range. In July, the CTMF spectra are surprisingly similar, both in magnitude and shape, to those in January, considering a hemispheric change in season (Fig. 4b).

It is noteworthy that the horizontal wavelengths associated with a relatively strong power of the CTMF shown in Fig. 4 are mostly shorter than $100 \mathrm{~km}$. This is because the CGWs considered in the present parameterization are those generated by local convective clouds (subgrid-scale convective clouds). It is also noteworthy that the vertical wavelength spectrum of the CTMF is wide, ranging from 1 to $100 \mathrm{~km}$. These scales of GWs are nearly unresolvable in GCMs, including recently reported high-resolution GCMs with horizontal resolutions of about $0.25^{\circ} \times 0.25^{\circ}$ (e.g., Liu et al. 2014), and in most satellite observations (e.g., Alexander et al. 2008; Yan et al. 2010; Ern and Preusse 2012; Preusse et al. 2014). Considering that these GWs have a significant impact in the middle atmosphere through the deposition of momentum, understanding the spectral characteristics of these CGWs and their spatiotemporal variations is required. This can be achieved best by offline calculation of a CGW parameterization that takes into account spatiotemporal variations in the source spectrum using global reanalysis data with a fine temporal resolution (hourly) for a relatively long period, as done in the present study. This is the main motivation of the current study.

\section{b. Temporal variations in selected regions}

Figure 5 shows the magnitude of CTMF in timelongitude cross sections from 1979 to 2010 at six latitudinal bands $\left(0^{\circ}-10^{\circ} \mathrm{N}, 0^{\circ}-10^{\circ} \mathrm{S}, 10^{\circ}-30^{\circ} \mathrm{N}, 10^{\circ}-30^{\circ} \mathrm{S}\right.$, $\left.30^{\circ}-50^{\circ} \mathrm{N}, 30^{\circ}-50^{\circ} \mathrm{S}\right)$, and Fig. 6 shows its power spectral density (PSD) in a zonal wavenumber and frequency domain. To calculate the PSD, daily CTMF are used after subtracting a 32-yr time-mean value. In each plot of Fig. 5, several peaks appear at certain longitudes and times. For example, at $10^{\circ}-30^{\circ} \mathrm{N}$ (Fig. 5c), the local maxima appear in the summer season at $60^{\circ}-110^{\circ} \mathrm{E}$, along with small peaks at $30^{\circ}-100^{\circ} \mathrm{W}$ throughout the entire season and at $150^{\circ} \mathrm{W}-180^{\circ}$ in the winter season. At $0^{\circ}-10^{\circ} \mathrm{S}$ and $10^{\circ}-30^{\circ} \mathrm{S}$ (Figs. $5 \mathrm{~b}, \mathrm{~d}$ ), several peaks appear between $10^{\circ} \mathrm{E}$ and $180^{\circ}$, and they move eastward during the boreal winter. They are likely related to MJO, considering that noticeable powers exist (Figs. 6a,b,d) at frequencies between 0.013 and 0.03 cycles per day (cpd), corresponding to approximately 33-77 days, and zonal wavenumbers less than 4 . Interestingly, the peaks of $\mathrm{CTMF}$ at $30^{\circ}-50^{\circ} \mathrm{S}$ show the strongest year-to-year variations among all latitude bands, and this is likely because storm tracks in the $\mathrm{SH}$ are not regularly formed over $30^{\circ}-50^{\circ} \mathrm{S}$, in contrast to the $\mathrm{NH}\left(30^{\circ}-50^{\circ} \mathrm{N}\right)$, where the storm tracks are formed at almost the same locations (western Pacific and western Atlantic Oceans). Several peaks of CTMF at $30^{\circ}-50^{\circ} \mathrm{N}$ are moving eastward $\left(60^{\circ}-150^{\circ} \mathrm{E}, 60^{\circ}-120^{\circ} \mathrm{W}\right)$, and strong powers exist at frequencies less than about $0.4 \mathrm{cpd}$ and zonal wavenumbers less than about 10 (Fig. 6e). The phase speed (slope in the wavenumber-frequency domain) of the eastward movement of CTMF at this latitude band is approximately $12-17 \mathrm{~m} \mathrm{~s}^{-1}$. Similar features are shown at $30^{\circ}-50^{\circ} \mathrm{S}$, although stronger powers exist at relatively high frequencies, and the eastward phase speed is faster $\left(22-31 \mathrm{~m} \mathrm{~s}^{-1}\right.$ ) than in $30^{\circ}-50^{\circ} \mathrm{N}$ (Fig. 6f).

In Fig. $5 \mathrm{c}\left(10^{\circ}-30^{\circ} \mathrm{N}\right)$, three peaks appear over monsoon regions during the boreal summer: the Asian monsoon region $\left(60^{\circ}-140^{\circ} \mathrm{E}\right)$, the American monsoon region $\left(60^{\circ}-120^{\circ} \mathrm{W}\right)$, and the African monsoon region $\left(0^{\circ}-50^{\circ} \mathrm{E}\right)$, and they are consistent with those in some previous studies using the HIRDLS observations (e.g., Wright and Gille 2011; Ern and Preusse 2012). Wright and Gille (2011) explained that the longitudinal peaks of the GWMF at $5 \mathrm{hPa}$ in the summer monsoon regions are mainly derived from the convective sources. However, the peaks in the African monsoon region $\left(0^{\circ}-50^{\circ} \mathrm{E}\right)$ during boreal summer are not evident in the observed precipitation and OLR of Wright and Gille (2011). This is consistent with Geller et al. (2015), who suggested that any CGW parameterization with the source momentum flux that is proportional to diabatic heating alone cannot represent the observed GWMF in the stratosphere. The CTMF calculated from the present study in the African monsoon region $\left(0^{\circ}-50^{\circ} \mathrm{E}\right)$ during boreal summer is relatively large compared with its $\mathrm{DCH}$ magnitude. In 


\section{Cloud-top momentum flux}

(a) $E Q-10^{\circ} \mathrm{N}$

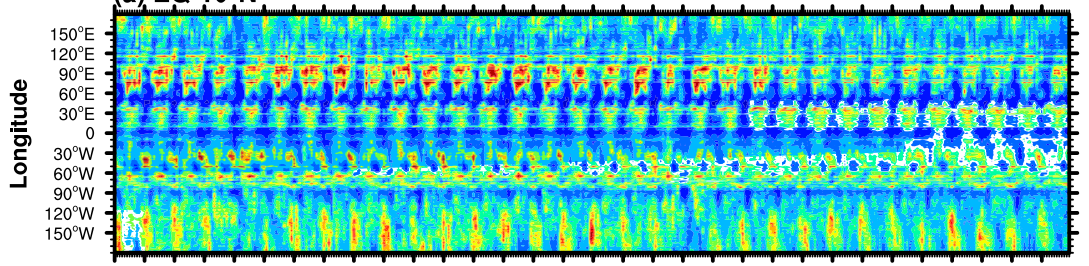

(b) EQ-10 $\mathrm{S}$

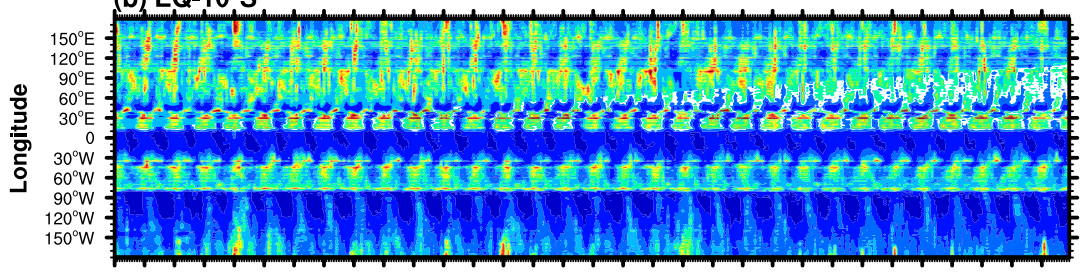

(c) $10^{\circ} \mathrm{N}-30^{\circ} \mathrm{N}$
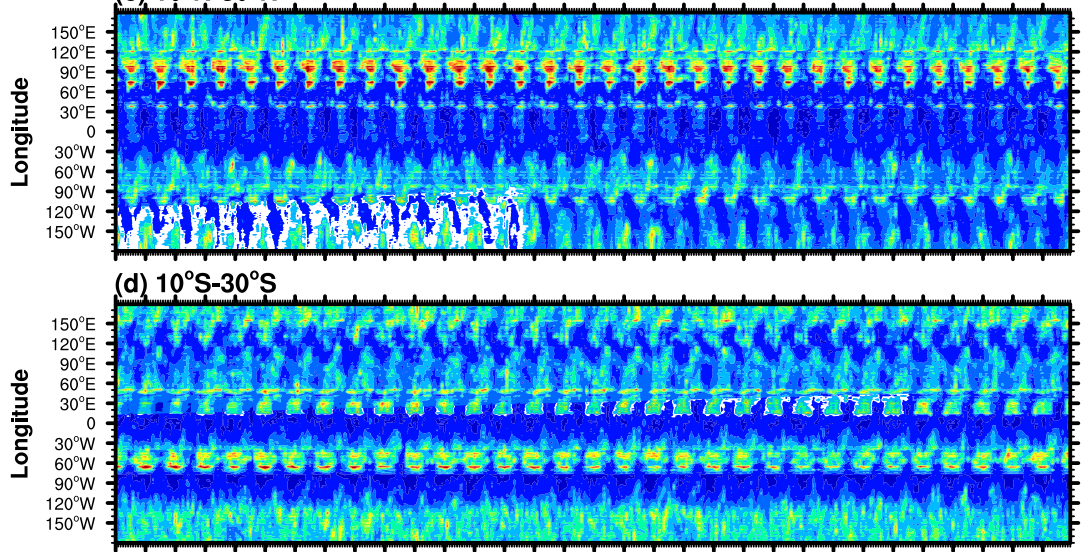

(e) $30^{\circ} \mathrm{N}-50^{\circ} \mathrm{N}$
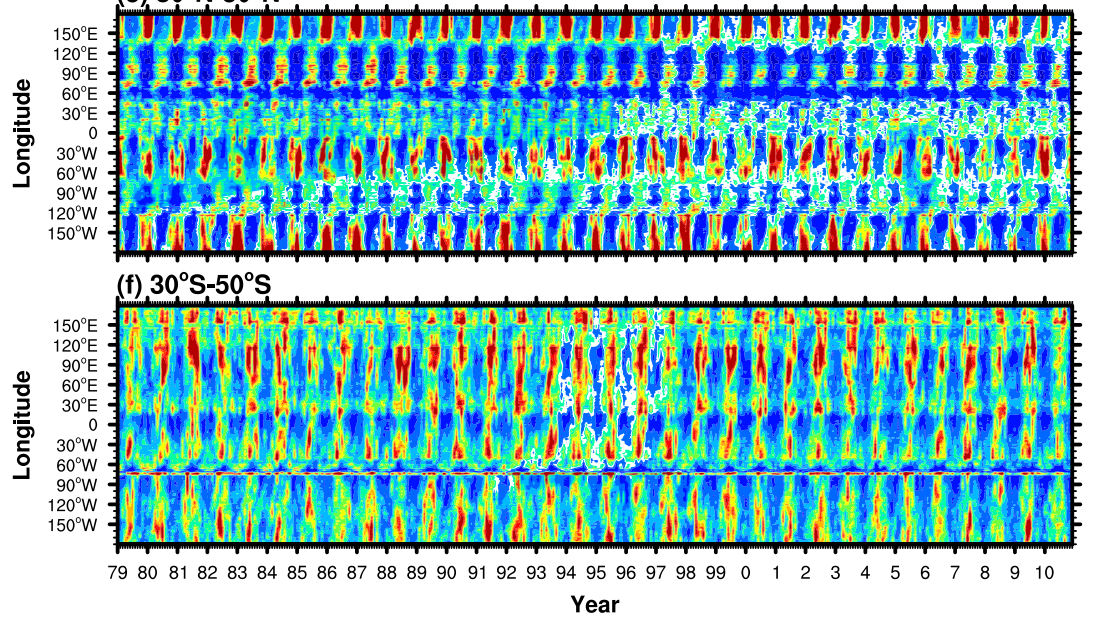

Year

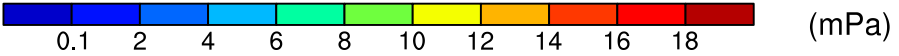

FIG. 5. Time-longitude cross sections of absolute CTMF averaged over (a) $0^{\circ}-10^{\circ} \mathrm{N}$,

(b) $0^{\circ}-10^{\circ} \mathrm{S}$, (c) $10^{\circ}-30^{\circ} \mathrm{N}$, (d) $10^{\circ}-30^{\circ} \mathrm{S}$, (e) $30^{\circ}-50^{\circ} \mathrm{N}$, and (f) $30^{\circ}-50^{\circ} \mathrm{S}$ from 1979 to 2010. 


\section{Power Spectral Density of CTMF}

(a) $E Q-10^{\circ} \mathrm{N}$

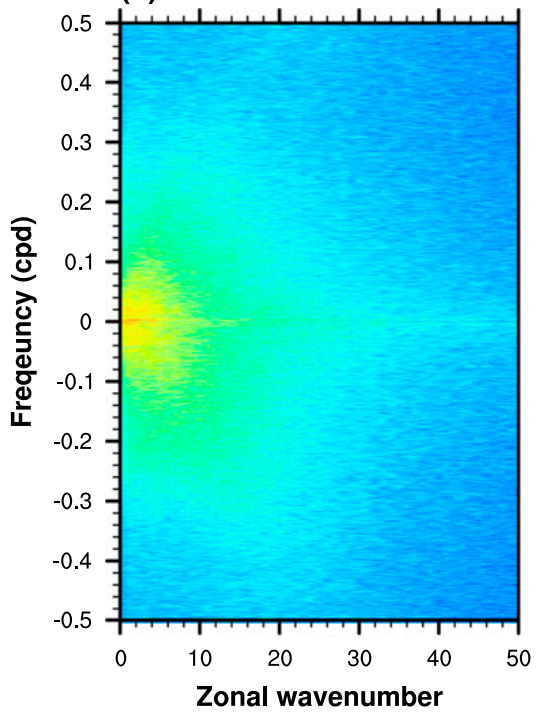

(d) $10^{\circ} \mathrm{S}-30^{\circ} \mathrm{S}$

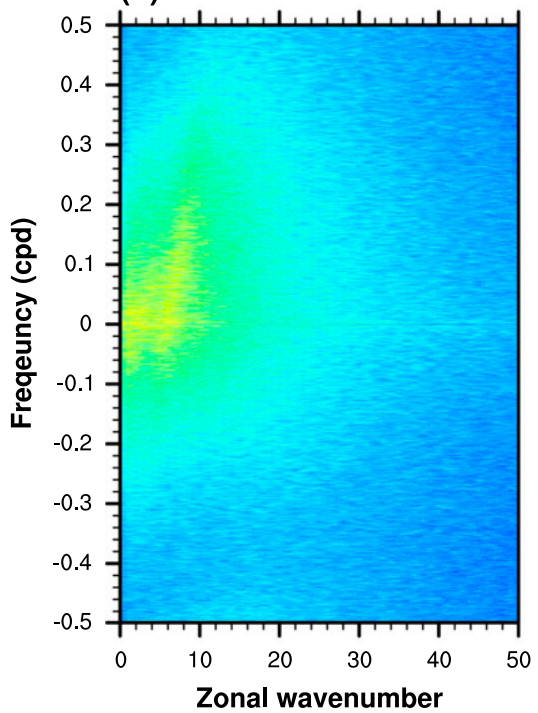

(b) EQ-10 $0^{\circ} \mathrm{S}$

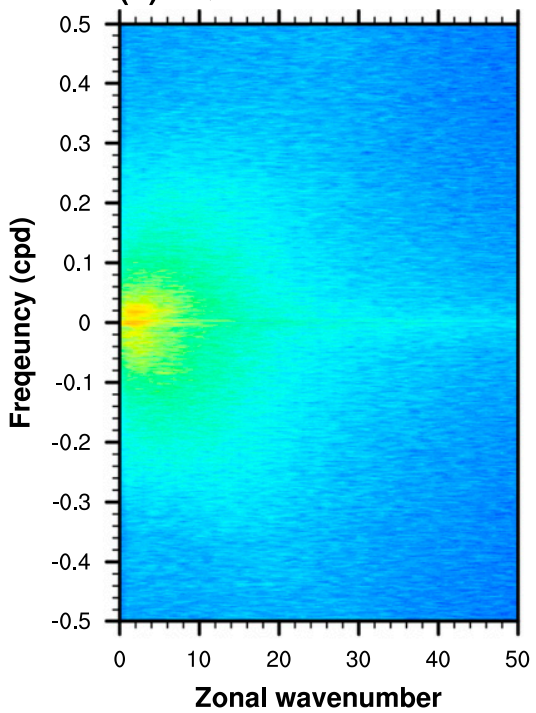

(e) $30^{\circ} \mathrm{N}-50^{\circ} \mathrm{N}$

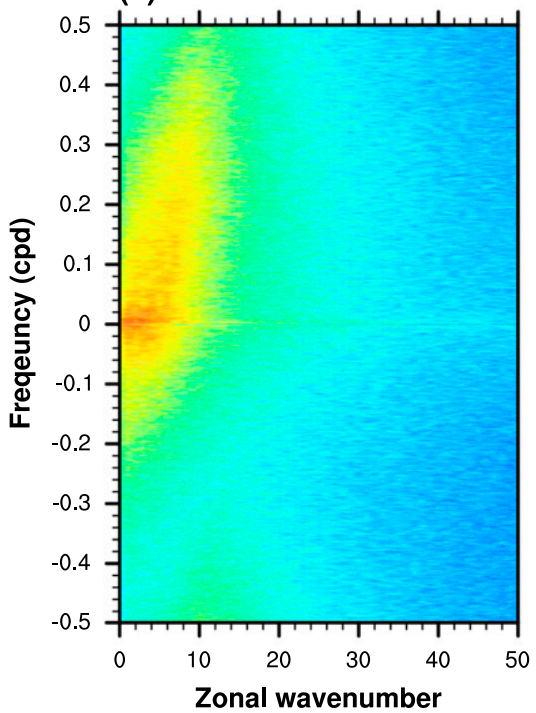

(c) $10^{\circ} \mathrm{N}-30^{\circ} \mathrm{N}$

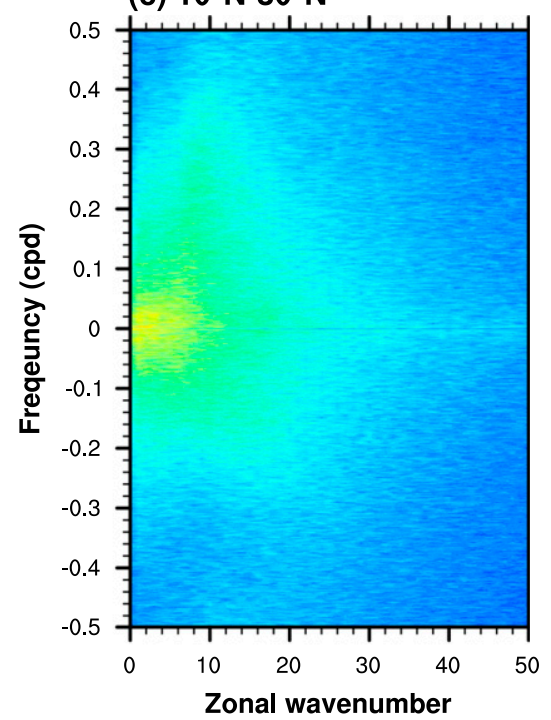

(f) $30^{\circ} \mathrm{S}-50^{\circ} \mathrm{S}$

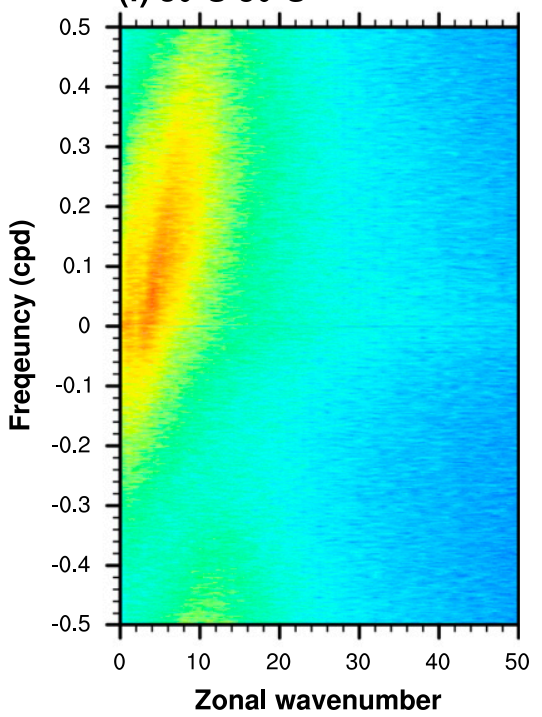

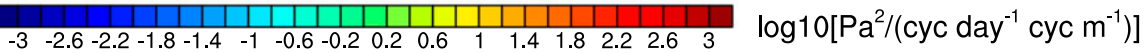

FIG. 6. Zonal wavenumber-frequency cross section of the PSD of daily CTMF for (a) $0^{\circ}-10^{\circ} \mathrm{N}$, (b) $0^{\circ}-10^{\circ} \mathrm{S}$, (c) $10^{\circ}-30^{\circ} \mathrm{N}$, (d) $10^{\circ}-30^{\circ} \mathrm{S}$, (e) $30^{\circ}-50^{\circ} \mathrm{N}$, and (f) $30^{\circ}-50^{\circ} \mathrm{S}$.

fact, the 32-yr mean of DCH in June-August over the African monsoon region is 5 (2.7) times smaller than that over the Asian (American) monsoon region, and the magnitude of CTMF is 3.2 (1.5) times smaller than the Asian (American) monsoon region. The relatively lower difference in the magnitude of CTMF between the African monsoon region and the other two monsoon regions compared with that of $\mathrm{DCH}$ is due to the several factors included in Eq. (1): smaller $T_{q}$ and $N_{q}$, lower cloud top (larger air density), and greater coincidence between convective source and WFRF spectra in the African monsoon region than the other monsoon regions. The direct comparison between the GWMF in the stratosphere from observations and that calculated from the current offline CGW parameterization will be given in Part II.

To examine the temporal variations in the CTMF at large CTMF regions, we choose the six regions shown in 
Fig. 7. Region 1 is the Atlantic storm-track region, region 2 is the Pacific storm-track region, region 3 is the Asian summer monsoon region, region 4 is the equatorial region in the eastern Pacific, region 5 is the stormtrack region in the $\mathrm{SH}$, and region 6 is located near the southern Andes. Figure 8 is the time series of the monthly mean of CTMF (black) and column-maximum $\mathrm{DCH}$ (red) averaged over each selected region. DCH is large in region 3 during summer and region 4 (low latitudes), whereas the CTMF is large in regions 1 and 2 (midlatitudes) during winter. The correlation between the CTMF and DCH (green number at the top right of each panel) is generally high, but relatively lower correlations are observed in region $4(0.73)$ and region 1 (0.91). That is, although the temporal change in CTMF at the local region is largely affected by the temporal change in the convective heating, other factors are likely to influence CTMF, especially in regions 1 and 4.

To examine how CTMF is correlated with each term constituting CTMF, the correlations between CTMF and all factors [DCH, WFRF, spectral combination between WFRF and convective source (WFRFxConv), $T_{q}$, and $N_{q}$ ) ] at each region are shown in Table 1. Generally, DCH shows the highest correlation with CTMF among all variables. However, the correlation between CTMF and WFRF is larger than the correlation between CTMF and $\mathrm{DCH}$ at region 6 , and those two correlation values are comparable to each other at regions 3 and 5. In region 4 , the correlation of CTMF with WFRF is lower than that with $\mathrm{DCH}$, but WFRFxConv shows higher correlation than DCH. This confirms that WFRF plays an important role in determining the shape and magnitude of CTMF through spectral combination with the convective source, more than WFRF itself (Fig. 2). This is also true in most regions.

Both $T_{q}$ and $N_{q}$, which are the air temperature and static stability averaged in the cloud depth, respectively, are negatively correlated with CTMF, because they are the denominators in the CTMF formulation [Eq. (2)]. Their contributions to CTMF are quite significant at most regions (Table 1) except at two tropical regions (regions 3 and 4). It is somewhat interesting for relatively low correlation of $T_{q}$ and $N_{q}$ with CTMF in the tropical regions, where deep convective clouds exist. We found that this is because $N_{q}$ and $T_{q}$ contribute to CTMF directly as the denominators of Eq. (2) and indirectly through other terms in CTMF, and these two effects work differently in the tropical and midlatitude regions. In the tropical regions where deep clouds exist, $N_{q}$ and $T_{q}$ are small, leading to large CTMF. In that situation, the spectral combination between WFRF and the convective source becomes small, as shown in Fig. 4 of SC05 and

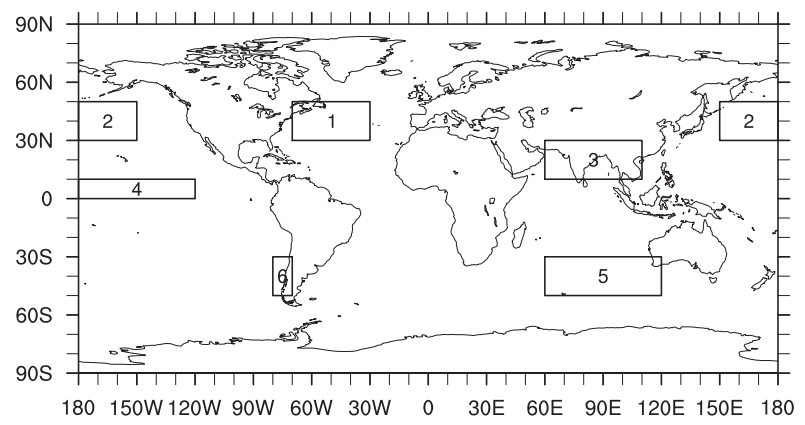

FIG. 7. Global map with six boxes in which the local maxima of the absolute CTMF appear. The six boxes are located in the Atlantic storm-track region at $30^{\circ}-50^{\circ} \mathrm{N}, 30^{\circ}-70^{\circ} \mathrm{W}$ (region 1); Pacific storm-track region at $30^{\circ}-50^{\circ} \mathrm{N}, 150^{\circ} \mathrm{E}-150^{\circ} \mathrm{W}$ (region 2); Asian summer monsoon region at $10^{\circ}-30^{\circ} \mathrm{N}, 60^{\circ}-110^{\circ} \mathrm{E}$ (region 3); equatorial eastern Pacific region at $0^{\circ}-10^{\circ} \mathrm{N}, 120^{\circ} \mathrm{W}-180^{\circ}$ (region 4); $\mathrm{SH}$ storm-track region at $30^{\circ}-50^{\circ} \mathrm{S}, 60^{\circ}-120^{\circ} \mathrm{E}$ (region 5); and southern Andes at $30^{\circ}-50^{\circ} \mathrm{S}, 70^{\circ}-80^{\circ} \mathrm{W}$ (region 6).

Fig. 2 of the current study, resulting in small CTMF. The aforementioned opposite contribution makes $N_{q}$ and $T_{q}$ less correlated with CTMF. In the midlatitude regions, $N_{q}$ and $T_{q}$ are small in wintertime where convective heating is maximum, resulting in large CTMF in wintertime (Fig. 8) and strong negative correlation with CTMF (Table 1). The time series of WFRF, WFRFxConv, $N_{q}$, and $T_{q}$ overlapped with CTMF are provided in the supplementary material (Figs. S1 and S2).

In all regions, the annual cycle is predominant (Figs. 8 and 9) with different seasonal maxima. The maximum CTMF occurs in winter at regions 1,2, 5, and 6 (stormtrack regions and southern Andes) and summer at regions 3 (summer hemisphere monsoon region) and 4 (equatorial region).

Figure 9 is the PSD of the CTMF in area-preserving form (black lines) with the red noise line at the $95 \%$ confidence level (red lines). It appears that the annual cycle, diurnal cycle, and subdiurnal cycle are noticeable at all regions. The powers at periods shorter than $6 \mathrm{~h}$ are above the red noise line at all regions, indicating characteristics of rapidly changing convection. The ratio of PSD of the 1-day period to that of the 1-yr period is greater at region 4 than any other regions, because convections exist regardless of season in the tropical region. PSDs over 2-12 days, likely related to synoptic phenomena, are greater at regions 1,2, 5, and 6 than at regions 3 and 4 . Another significant periodicity is 6 months, especially at regions 2,3 , and 4 . The overhead sun crossing the equator twice in a year is likely to be related to a 6-month cycle of $\mathrm{DCH}$ in the equatorial region (region 4). In region 3 , the primary local peak of CTMF appears (not shown) along the western coast of 

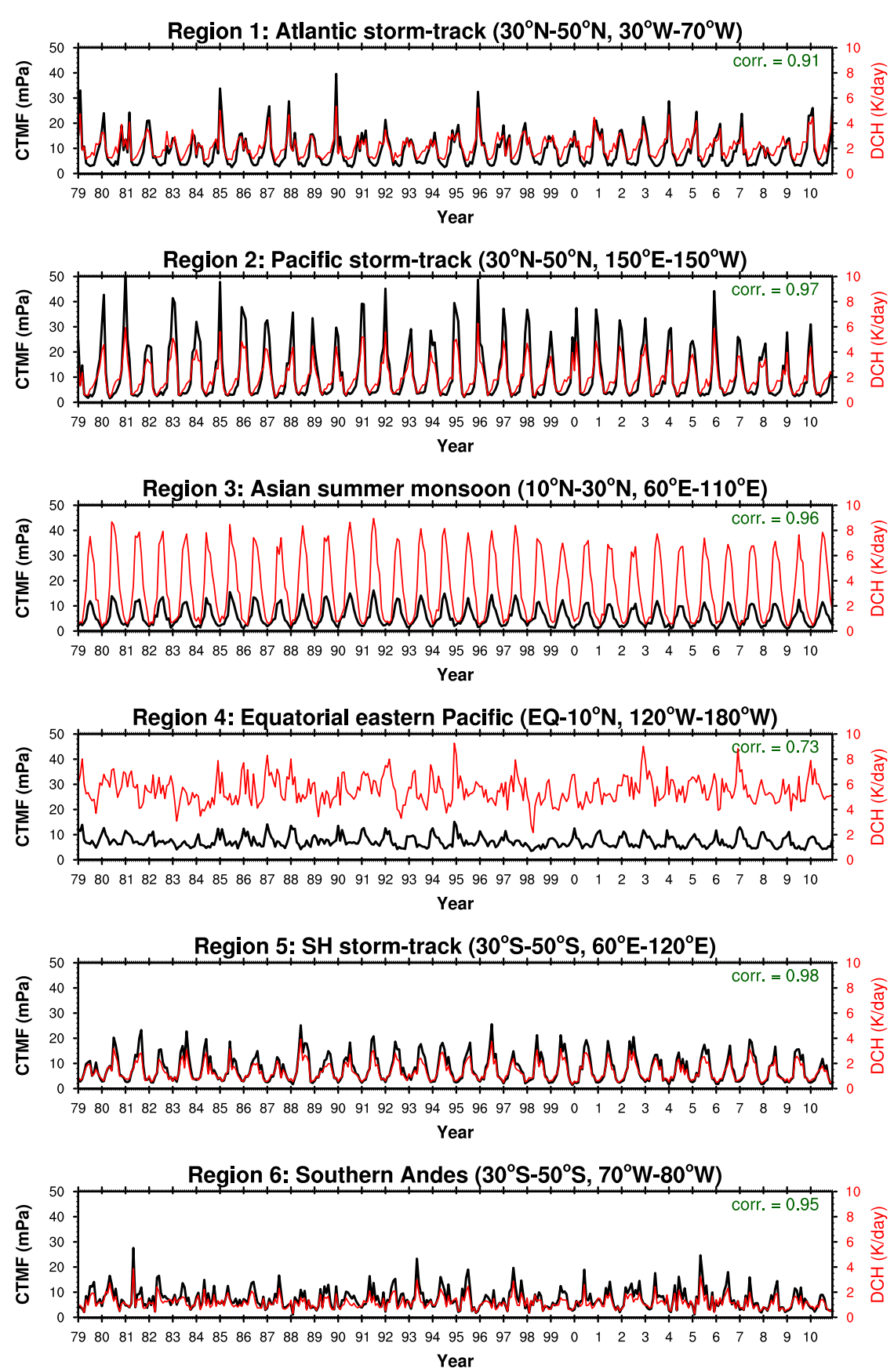

FIG. 8. Time series of monthly mean absolute CTMF (black line) and column-maximum DCH (red line) averaged over (top)-(bottom) regions 1-6 from 1979 to 2010. The axis of CTMF (DCH) is plotted on the left (right) axis of the figure. Green text in the upper-right corner of each panel represents correlation between CTMF and DCH.

India and Myanmar in July and the secondary local peak on the northeastern side of India between March and May and in October (not shown), as also shown in the convective activities from previous observational studies by Roy Bhowmik et al. (2008) and Dhaka et al. (2010). This leads to the semiannual cycle of region 3. In region 2, the CTMF and DCH show their primary peaks in winter, along with very small secondary peaks in the summer (Fig. 8), and this leads to the 6-month cycle in Fig. 9. The 6-month period of latent heat release in region 2 has also been reported in previous studies (Newton 2004; Chen and Tsay 2014). The 6-month cycle, 
TABLE 1. Correlation between absolute CTMF and magnitude of several variables (DCH, WFRF, WFRFxConv, $T_{q}$, and $N_{q}$ ) at (left to right) regions 1-6. Statistically significant correlations at the $95 \%$ confidence level by a two-tailed $t$ test are in boldface.

\begin{tabular}{|c|c|c|c|c|c|c|}
\hline & \multicolumn{6}{|c|}{ Correlation with CTMF } \\
\hline & Region 1 & Region 2 & Region 3 & Region 4 & Region 5 & Region 6 \\
\hline $\mathrm{DCH}$ & 0.91 & 0.97 & 0.96 & 0.73 & 0.98 & 0.95 \\
\hline WFRF & 0.68 & 0.92 & 0.95 & 0.60 & 0.97 & 0.96 \\
\hline WFRFxConv & 0.97 & 0.97 & 0.98 & 0.82 & 0.97 & 0.95 \\
\hline$T_{q}$ & -0.73 & -0.77 & -0.36 & 0.05 & -0.78 & -0.47 \\
\hline$N_{q}$ & -0.77 & -0.79 & -0.09 & 0.06 & -0.80 & -0.44 \\
\hline
\end{tabular}

however, does not stand out in the Atlantic storm tracks (region 1).

There are interannual variations at region $4(\sim 2$ and $4-12$ years), region 6 ( $\sim 11$ years), and region $2(12-16$ years). The $\sim 2$-yr cycles at region 4 could be linked to the QBO by the modulation of the convective activity with respect to QBO phases [see Figs. 3-5 of Liess and Geller (2012)]. Also, periods longer than 4 years can be related to ENSO and long-term variability of ENSO, given that region 4 is in the east Pacific region. Regions 5 and 6 have various scales of year-to-year variations, as consistent with Fig. 5. Region 6 exhibits a statistically significant decadal variation at $\sim 11$ years. The PSD at 12-16 years is the largest at region 2 among the six regions, although it does not exceed the red noise curve. The decadal variations at regions 2 and 6 (extratropical regions in the Pacific) are influenced by Pacific decadal oscillation (PDO; Newman et al. 2016). In particular, a correlation between yearly PDO and CTMF (not shown) at region 2 is 0.4 , which is statistically significant at the $95 \%$ confidence level (two tailed). Note that PDO is usually characterized by the variabilities in the North Pacific sea surface temperature (Mantua and Hare 2002), but the impacts also extend to the SH. Given that the CTMF is the combination of convective heating, basic-state wind, and stability, several climate variabilities can be simultaneously associated with the variations in CTMF.

Figure 10 depicts time variations in the zonal CTMF spectrum over a time-phase speed cross section. At all regions, the CTMF spectra have a predominant annual cycle, although this is less evident at regions 4 and 6 . The zero line of the CTMF is at the phase speed equal to the zonal wind at the cloud top $\left(c=U_{\mathrm{ct}}\right)$. Following the changes in the background wind, the zero-CTMF line also varies with time. Although the positive and negative momentum spectra of CTMF at each region appear similar, they are asymmetric because of spectral combination of the convective source and WFRF spectra, as shown in Fig. 2. The positive momentum is dominant at region 3 during the summer and at region 4 , where the background wind at the cloud top is easterly and the convection is moving eastward relative to the background flow, while the negative momentum is dominant during the winter for all regions, where the background wind is westerly and the convection is moving westward relative to the background wind. In the equatorial region (e.g., region 4), where the background wind and its variance at the cloud top are very small, the variations in CTMF are affected mostly by those in the spectral shape of the convective source, which is determined largely by the moving speed of convection $\left[c_{q h}\right.$ in Eq. (2)], the magnitude of the convective heating rate, and the spectral shape of WFRF.

The strong seasonal changes in the phase speed spectrum occur at region 3 , the Asian summer monsoon region, by a seasonal reversal of wind. The spectral width at region 3 is also the largest for both the positive and negative momentum fluxes, with phase speed ranges of nearly $\pm 100 \mathrm{~m} \mathrm{~s}^{-1}$. The width of the CTMF spectrum is influenced by the WFRF spectrum, which is highly correlated with the heating depth. The wide spectrum width at region 3 in summer and region 4 are due to deep convections frequently excited in these regions. In the $\mathrm{NH}$, the CTMF at region 1 shows a slightly wider spectrum than at region 2, especially for negative momentum flux, even though the two regions are located at the same latitudes, and this is because of a wider WFRF induced by deeper clouds at region 1 than region 2 . Region 5 in the SH shows a narrower CTMF spectrum than at the similar latitude of the $\mathrm{NH}$ (regions 1 and 2); this is also because of the shallower clouds at region 5 than at regions 1 and 2 .

At region 4 , both positive and negative momentum fluxes have a wide spectrum throughout the whole periods, and this implies that the CGWs in this region can still carry a large amount of momentum at high altitudes without significant filtering by the background wind in the middle atmosphere. It is noteworthy that not only the spectral shape but also the magnitude of CTMF is important for the momentum flux and GWD in the middle atmosphere, given that the magnitude of CTMF 

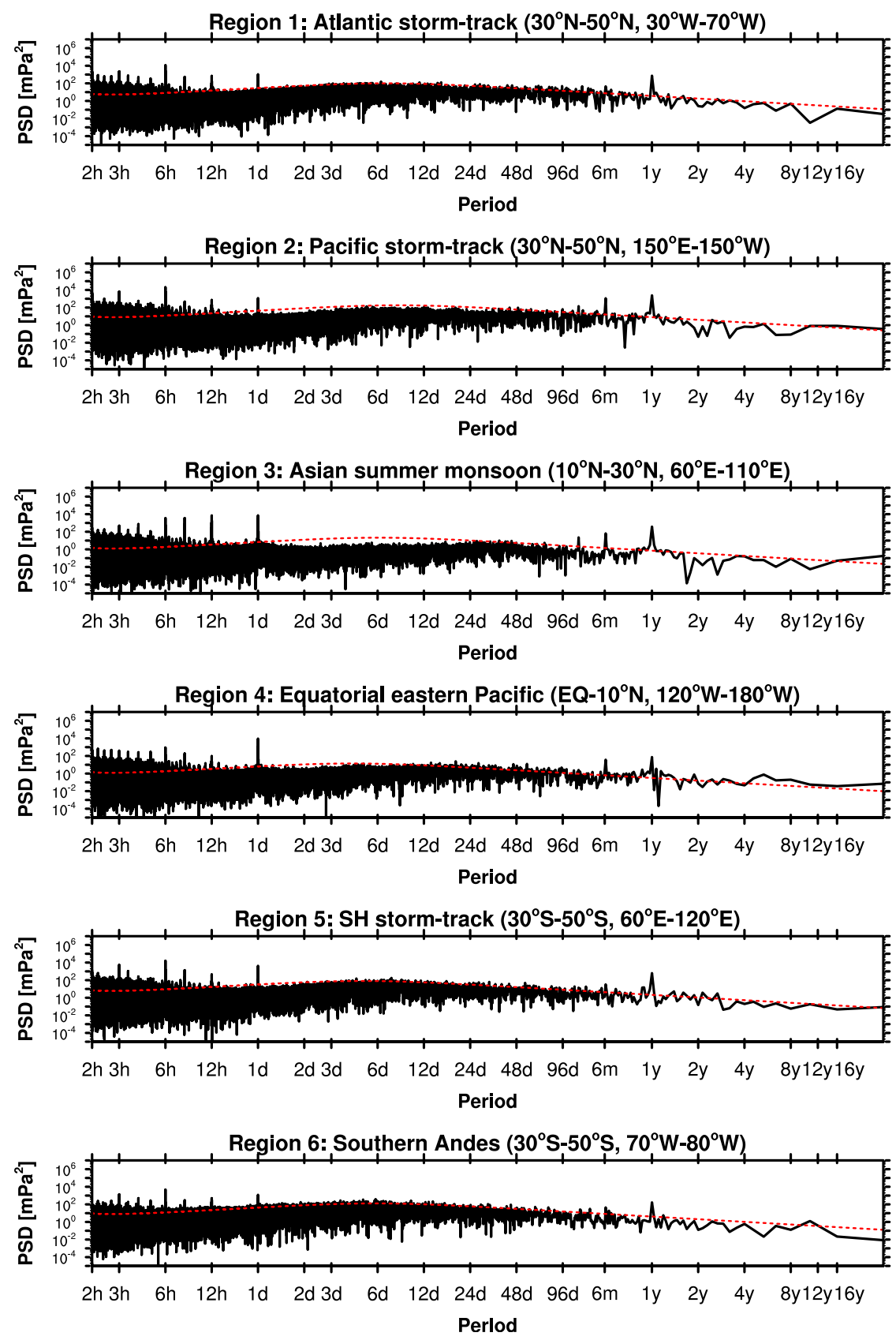

FIG. 9. PSD of absolute CTMF in the six regions (black solid) and the corresponding red noise spectrum (red dotted) at the $95 \%$ confidence level. The spectrum is presented in the area-preserving form for the log-scale axis.

is a crucial factor to determine the location of wave breaking and magnitude of the GWD forcing for the large-scale motion. Only the physically based and sourcedependent GWD parameterization can take into account temporal and spatial variations in the magnitude and spectral shape of source-level momentum flux, which is required for realistic representation of CGWs in the
GCMs for simulations of important atmospheric oscillations in the tropical stratosphere, such as the QBO (e.g., Kim et al. 2013; Richter et al. 2014; Schirber et al. 2014), and of extratropical circulation, such as the $\mathrm{SH}$ polar night jet (e.g., Choi and Chun 2013).

It is noteworthy that deep convective heating depth and convective precipitation of CFSR are systematically 

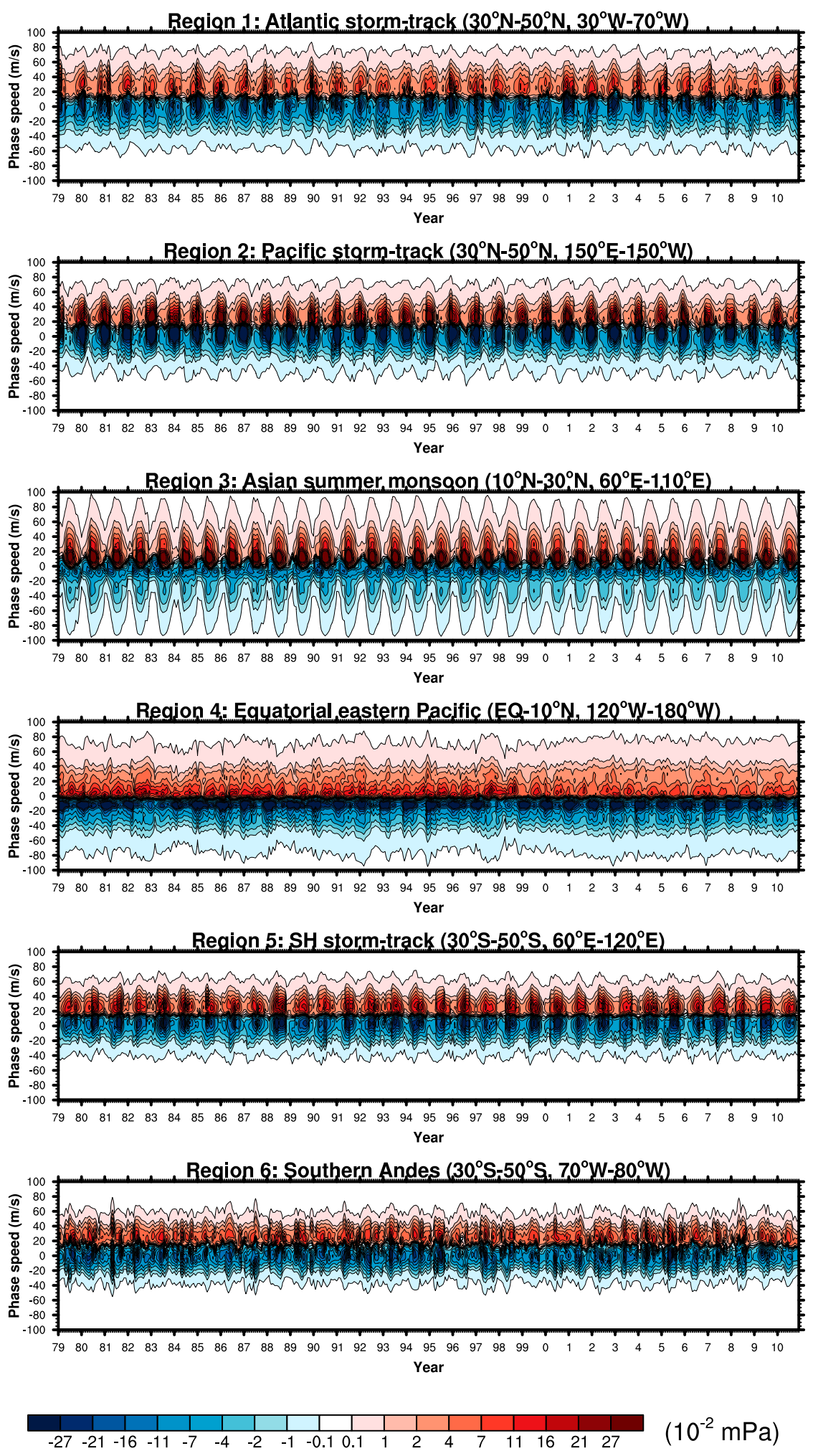

FIG. 10. Zonal CTMF spectra averaged over (top)-(bottom) regions 1-6 plotted against time ( $x$ axis) and phase speed ( $y$ axis) from 1979 to 2010. 
TABLE 2. Long-term trend of CTMF (mPa decade $\left.{ }^{-1}\right)$ and DCH $\left(\mathrm{K} \mathrm{day}^{-1}\right.$ decade $\left.^{-1}\right)$ during the total period (1979-2010), P1 (1979-98), and P2 (2000-10) for (left)-(right) regions 1-6. Statistically significant trends at the $90 \%$ confidence level using a $t$ test are in boldface.

\begin{tabular}{|c|c|c|c|c|c|c|c|}
\hline & & \multicolumn{6}{|c|}{ Long-term trend of CTMF and DCH } \\
\hline & & Region 1 & Region 2 & Region 3 & Region 4 & Region 5 & Region 6 \\
\hline \multirow[t]{2}{*}{ Total period } & CTMF & -0.133 & -0.951 & -0.332 & -0.379 & -0.272 & -0.386 \\
\hline & $\mathrm{DCH}$ & 0.050 & -0.040 & 0.070 & -0.010 & -0.021 & $-\mathbf{0 . 0 5 3}$ \\
\hline \multirow[t]{2}{*}{$\mathrm{P} 1$} & CTMF & -0.060 & -0.196 & 0.220 & -0.493 & 0.315 & -0.226 \\
\hline & $\mathrm{DCH}$ & 0.009 & 0.018 & 0.091 & -0.111 & 0.047 & -0.053 \\
\hline \multirow[t]{2}{*}{$\mathrm{P} 2$} & CTMF & -0.404 & -4.413 & 0.341 & -1.006 & -1.382 & -2.372 \\
\hline & $\mathrm{DCH}$ & 0.005 & -0.465 & 0.230 & -0.064 & -0.224 & -0.295 \\
\hline
\end{tabular}

large after 1999, which causes a statistically significant long-term trend. This is due to the changes in the assimilated radiance from TIROS Operational Vertical Sounder (TOVS) to Advanced TOVS (ATOVS; Wang et al. 2011), and it seems evident in the hydrological quantities (e.g., precipitation and precipitable water). Keeping in mind this change, we calculated the CTMF and DCH trends at each region before (P1: 1979-98) and after (P2: 2000-10) 1999, along with the trend for the whole period (1979-2010), and they are shown in Table 2. Several interesting features are found in Table 2. For the whole period, the CTMF in all regions shows a decreasing trend, but only the decreasing trend at region 4 is statistically significant at the $90 \%$ confidence level by a $t$ test (Wilks 2006). At high-latitude regions (regions 1, 2 , 5, and 6), negative trends of both DCH and CTMF in P2 are enhanced significantly. In particular, at the $\mathrm{NH}$ and SH storm-track regions (region 2 and 5, respectively), the weak positive trend of $\mathrm{DCH}$ in $\mathrm{P} 1$ is changed to be a strong negative trend. Region 3 is the only location where DCH and CTMF have all positive trends in P1 and $\mathrm{P} 2$ periods. This can be distinguished from region 4 (equatorial eastern Pacific), where negative trends exist for DCH and CTMF. At region 1, DCH has a positive trend for both periods, while CTMF has negative ones, especially in P2. This implies that the prospects of CGW activities in a changed climate should be significantly different from each region and are not solely determined by changes in convective activities.

\section{Intermittency in CTMF}

GW intermittency is a well-known characteristic of GWs, which is evident from various datasets, such as superpressure balloon observations, satellite observations, and high-resolution numerical simulation results (e.g., Hertzog et al. 2008; Alexander et al. 2010; Hertzog et al. 2012; Wright et al. 2013). The intermittency refers to variations in GW activity in space and time. The significant changes in GW amplitudes arise from time- varying wave packets at the forcing region and the background conditions. Thus, the GWs observed at a certain point do not exhibit a universal spectrum slope (VanZandt 1982; Fritts et al. 1988) in a single snapshot, and the universal spectrum can be obtained only when inhomogeneous spectra are averaged over a certain period of time (Hertzog et al. 2012). Several previous studies have reported that the wave intermittency observed in the lower stratosphere is not derived solely from variations in the wave propagation condition between the source level and the observed altitude (e.g., background wind) but also from the variations in the GW source itself (Fritts and Alexander 2003; de la Cámara et al. 2014). For example, the transient nature of the background conditions (wind speed, direction, and stability) around the mountain height leads to the intermittent behavior of the source-level momentum flux of mountain GWs (Smith 1979), regardless of a stationary mountain source. The CGWs are much more complicated than the mountain GWs in that the convection (diabatic heating rate, depth, and top and bottom heights) as well as the background stability and inflow impinging on the convection are transient, which together affect the intermittent behavior of CGWs. In the CTMF parameterization, the intermittency of the background stability, large-scale wind, and the top and bottom heights of convective cloud determines the intermittency of WFRF, which results in the intermittency of CTMF, together with the intermittency of convective clouds.

In this study, we examine the intermittency of the source-level momentum flux of CGWs by calculating the probability density function (PDF) of the CTMF and the proportion of wave momentum flux of 90th and 99th percentiles to the total momentum flux. Figure 11 shows the PDF of the hourly CTMF between $10^{\circ} \mathrm{N}$ and $10^{\circ} \mathrm{S}$ from 11 February to 8 May 2010. We choose this location and time to compare with the observational study by Jewtoukoff et al. (2013), who showed GWs observed from long-duration superpressure balloons (SPBs) in 


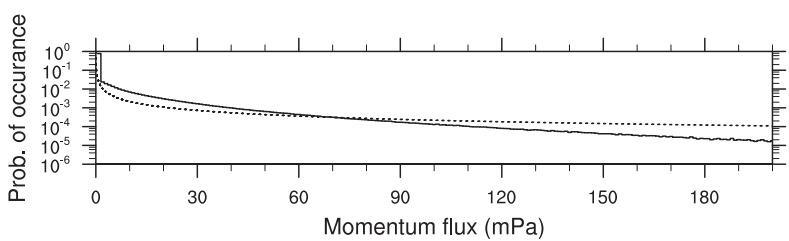

FIG. 11. PDFs of absolute CTMF between 8 Feb and 11 May 2010 over $10^{\circ} \mathrm{N}-10^{\circ} \mathrm{S}$ (solid line). Theoretical lognormal distribution is plotted with the same mean and standard deviation as the distribution in CTMF (dotted line).

the pre-Concordiasi campaign, focusing on the tropical region. Although the observed GWs in SPBs are in the lower stratosphere $(\sim 19 \mathrm{~km})$, it is close to the cloud-top height in the tropical region $\left(10^{\circ} \mathrm{N}\right.$ and $\left.10^{\circ} \mathrm{S}\right)$, considering deep convective clouds there. The overall shape of CTMF (solid line) follows a theoretical lognormal distribution (dotted line) reasonably well as in Fig. 16 of Jewtoukoff et al. (2013), although slight underestimation occurs at the CTMF larger than $70 \mathrm{mPa}$. The mean CTMF is $4.6 \mathrm{mPa}$, and the 90th and 99th percentiles are 10.5 and $79.5 \mathrm{mPa}$, respectively. The 90th (99th) percentile of CTMF corresponds to 2.3 (17.2) times the mean momentum flux, and this is similar to (larger than) that by Hertzog et al. (2012) of 2 (10) times. The momentum flux above the 90th (99th) percentile accounts for $88 \%$ (30\%) of the total momentum flux. From the mesoscale simulation of CGWs over the continental United States by Stephan et al. (2016), the 99th percentile explains only $10 \%$ of the total GW momentum flux at $z=15 \mathrm{~km}$. However, from the CGW parameterization based on a stochastic approach by de la Cámara et al. (2014), the 90th and 99th percentiles of momentum flux at $z=20 \mathrm{~km}$ in the $\mathrm{SH}$ summertime account for total wave momentum fluxes of $74 \%$ and $21 \%$, respectively. They also showed that when background GWs, which are generated from unknown sources, are included, the percentage of the wave momentum flux of the 90th and 99th percentiles become $48 \%$ and $10 \%$, respectively [see Fig. 2 of de la Cámara et al. (2014)]. In summary, the CTMF calculated from the current study follows the lognormal distribution reasonably well, without multiplying any factor, and a relatively large portion of CGWs carry large momentum flux in the present deterministic parameterization.

\section{Summary and discussion}

In this study, we updated the cloud-top (source level) momentum flux (CTMF) of CGW parameterization by CC11 by including the nonlinear forcing effects and examined the spatiotemporal variations in the magnitude and spectral shape of the CTMF based on a 32-yr (1979-2010) offline calculation of the parameterization using hourly CFSR data with a horizontal grid spacing of $1^{\circ} \times 1^{\circ}$. The CTMF is the largest in winter hemisphere storm tracks, where a secondary peak of convective heating exists, whereas the secondary maximum of the CTMF occurs in the ITCZ and summer hemisphere tropics, where a primary peak of convective heating exists. This is because the CTMF is determined by spectral combination of the convective source and the wave-filtering and resonance factor (WFRF), which contains the vertical propagation of GWs and the resonance between vertical harmonics consisting of the convective source and vertical modes determined by the dispersion relationship of internal gravity waves. The WFRF is minimal at the phase speed of the maximum convective source spectrum in the tropical region, while WFRF is in phase with the convective source spectrum in the storm tracks, which leads to the large spectral combination of WFRF and the convective source and a resultant large CTMF spectrum in the storm tracks. In addition, several variables in the convection region, such as temperature and particularly stability, affect the magnitude of CTMF.

The vertical- and horizontal-wavelength spectra of CTMF reveal that CGWs with vertical wavelengths ranging from 1 to $40 \mathrm{~km}$ and horizontal wavelengths ranging from 8 to $100 \mathrm{~km}$ are dominant, with the spatial $\left(\delta_{h}\right)$ and time $\left(\delta_{t}\right)$ scales of convective forcing set to $5 \mathrm{~km}$ and $20 \mathrm{~min}$, respectively. In the tropical region, the CTMF spectrum is distributed in relatively wide ranges of horizontal and vertical wavelengths, and this implies that CGWs in the tropical region can carry their momentum to the middle atmosphere efficiently without filtering by the background wind, regardless of the smaller magnitude of the source-level momentum flux (CTMF) than in the winter hemisphere storm tracks.

Temporal variations in the CTMF at six selected regions of high CTMF are examined: the Atlantic storm-track region (region 1), the Pacific storm-track region (region 2), the Asian summer monsoon region (region 3), the equatorial region in the eastern Pacific (region 4), the stormtrack region in the SH (region 5), and the southern Andes (region 6). All regions show strong annual and diurnal cycles, and some regions (regions 2,3, and 4) show significant 6-month cycles as well. In high-latitude regions, there are significant powers at a period of a few days related to the synoptic-scale disturbances. Interannual and decadal variations are also shown, although they vary in each region, and they are strongly related to the variations in the convective activities. The shape and width of the CTMF spectra, generally anisotropic and asymmetric, vary with time and space because of changes in the background wind and stability at the cloud top and the moving speed of convection. The CTMF generates large and intense events 
following the lognormal distributions relatively well, without multiplying any intermittency factor. The 99th percentile of CTMF accounts for the larger portion of total GWs compared with some observations, which is somewhat expected, given that GWs generated by local convective sources carry larger momentum flux than observed GWs that are generated by all available sources.

This study aimed to examine the spatiotemporal variations in the source-level momentum flux of GWs generated by local convective sources, such as subgridscale cumulus convection in GCMs, with horizontal wavelengths less than $\sim 100 \mathrm{~km}$ and vertical wavelengths up to $40 \mathrm{~km}$. These scales of CGWs carry large momentum flux when they propagate up to the middle atmosphere and deposit a significant amount of wave drag where they dissipate. Because any global observations and GCMs, including recent high-resolution GCMs with a horizontal grid spacing of $\sim 0.25^{\circ}$, cannot resolve these scales of GWs explicitly, we used a CGW parameterization that is based on a sound theory and is validated by mesoscale simulations and observations. To minimize the impact of unrealistic background flow on the CTMF and to maximize the transient nature of convective sources, the offline calculation of the CGW parameterization using hourly forecast fields from 32-yr global reanalysis data with a fine horizontal resolution $\left(1^{\circ}\right)$ is conducted instead of the GCM simulations including the same CGW parameterization (e.g., Kim and Chun 2015).

There are some limitations in the current study associated with information in the convective clouds provided from the global reanalysis data, such as the location and magnitude of convective heating and cloud-top and cloudbottom heights, which are generally model-produced data without including the observational data. In addition, the CFSR precipitation and column-integrated DCH are systematically large after 1999 compared to before, which leads to a statistically significant long-term trend that may not be physical in natures. This is likely due to the changes in the assimilated radiance from TOVS to ATOVS (Wang et al. 2011; Zhang et al. 2012). This change can affect humidity and temperature profiles in the assimilation process (English et al. 2000), resulting in artificial differences in the convective process before and after 1999. Other variables such as wind and temperature fields also influence the current results. Therefore, the current results can be sensitive to the choice of reanalysis data. Also, CTMF distribution is sensitive to the parameters setting in the CGW parameterization. Although those parameters are selected based on available observations and previous numerical modeling results, uncertainties in those parameters to apply global calculation of CTMF exist, given that the observations and numerical modeling results are given in the limited geographical locations and seasonal conditions. Nevertheless, the CGW momentum flux data at high temporal and spatial resolutions obtained from the current study can be utilized in research on CGWs and middleatmosphere dynamics and in various research areas related to the atmospheric oscillations associated with convection, such as MJO, QBO, and ENSO. In Part II, the stratospheric GW momentum flux and drag are calculated from the CTMF calculated in the present study, and the contribution of CGWs to the large-scale flow, including QBO will be presented.

Acknowledgments. This work was funded by the Korea Meteorological Administration Research and Development Program under Grant KMIPA 20156160. The NCEP CFSR data were downloaded from the Research Data Archive at the National Center for Atmospheric Research, Computational and Information Systems Laboratory, Boulder, Colorado (available online at http://dx.doi.org/10.5065/D69K487J), and from the National Oceanic and Atmospheric Administration (NOAA) Operational Model Archive and Distribution System, National Climatic Data Center, Asheville, North Carolina (available online at http://nomads.ncdc. noaa.gov/modeldata/cmd_pgbh/). The authors thank the anonymous reviewers for many helpful comments and suggestions. We would also like to thank Dr. In-Sun Song and Dr. Hyun-Joo Choi for their helpful advice on this study.

\section{APPENDIX}

\section{Determination of Vertical Profile of Convective Forcing}

The CTMF formulation is derived with an assumption that the vertical profile of convective heating $\zeta_{q}$ follows a second-order polynomial shape:

$$
\zeta_{q}=\left\{\begin{array}{cc}
1-\left[\left(z-z_{m}\right) / z_{d}\right]^{2} & z_{\mathrm{cb}} \leq z \leq z_{\mathrm{ct}} \\
0 & \text { elsewhere }
\end{array}\right.
$$

where $\quad z_{m}=\left(z_{\mathrm{ct}}+z_{\mathrm{cb}}\right) / 2, \quad z_{d}=\left(z_{\mathrm{ct}}-z_{\mathrm{cb}}\right) / 2, \quad$ and $\quad z_{\mathrm{ct}}$ and $z_{\mathrm{cb}}$ are the cloud-top and cloud-bottom height, respectively. We estimate $z_{\mathrm{ct}}$ and $z_{\mathrm{cb}}$ from the given reanalysis data: top $p_{\text {ctr }}$ and bottom pressure $p_{\text {cbr }}$ of the convective cloud and the $\mathrm{DCH}$ profile. Going downward (upward) from an altitude of $p_{\text {ctr }}\left(p_{\text {cbr }}\right)$, the level at which the DCH value first exceeds $4 \times 10^{-6} \mathrm{~K} \mathrm{~s}^{-1}$ is set to $z_{\mathrm{ct}}\left(z_{\mathrm{cb}}\right)$. The value $4 \times 10^{-6} \mathrm{~K} \mathrm{~s}^{-1}$ is determined empirically such that the fitted heating profile is similar to the actual profile. This methodology is somewhat different 
from that used in the previous study by Song et al. (2007) in which $z_{m}$ was defined as the DCH-weighted mean altitude and $z_{d}$ as the $\mathrm{DCH}$-weighted standard deviation of $z$ [see appendix in Song et al. (2007)]. The primary merit of the current approach is that it retains cloud-top-height information close to the real cloud-top height, and consequently, more deep clouds are available in the tropics. This results in more spectral powers at longer verticalwavelength components of CGWs in the tropical region, through resonance between waves with long vertical wavelength from convective sources and those from natural wave modes.

\section{REFERENCES}

Alexander, M. J., and J. R. Holton, 1997: A model study of zonal forcing in the equatorial stratosphere by convectively induced gravity waves. J. Atmos. Sci., 54, 408-419, doi:10.1175/ 1520-0469(1997)054<0408:AMSOZF>2.0.CO;2.

- and Coauthors, 2008: Global estimates of gravity wave momentum flux from High Resolution Dynamics Limb Sounder observations. J. Geophys. Res., 113, D15S18, doi:10.1029/ 2007JD008807.

- and Coauthors, 2010: Recent developments in gravity-wave effects in climate models and the global distribution of gravitywave momentum flux from observations and models. Quart. J. Roy. Meteor. Soc., 136, 1103-1124, doi:10.1002/qj.637.

Baldwin, M. P., and Coauthors, 2001: The quasi-biennial oscillation. Rev. Geophys., 39, 179-229, doi:10.1029/1999RG000073.

Baumgaertner, A. J. G., and A. J. McDonald, 2007: A gravity wave climatology for Antarctica compiled from Challenging Minisatellite Payload/Global Positioning System (CHAMP/GPS) radio occultations. J. Geophys. Res., 112, D05103, doi:10.1029/ 2006JD007504.

Beres, J. H., M. J. Alexander, and J. R. Holton, 2002: Effects of tropospheric wind shear on the spectrum of convectively generated gravity waves. J. Atmos. Sci., 59, 1805-1824, doi:10.1175/1520-0469(2002)059<1805:EOTWSO > 2.0.CO;2.

,-- , and — 2004: A method of specifying the gravity wave spectrum above convection based on latent heating properties and background wind. J. Atmos. Sci., 61, 324-337, doi:10.1175/ 1520-0469(2004)061<0324:AMOSTG > 2.0.CO;2.

Chen, T.-C., and J.-D. Tsay, 2014: Development and maintenance mechanism for the semiannual oscillation of the North Pacific upper-level circulation. J. Climate, 27, 3767-3783, doi:10.1175 JCLI-D-12-00418.1.

Choi, H.-J., and H.-Y. Chun, 2011: Momentum flux spectrum of convective gravity waves. Part I: An update of a parameterization using mesoscale simulations. J. Atmos. Sci., 68, 739-759, doi:10.1175/2010JAS3552.1.

_ and - 2013: Effects of convective gravity wave drag in the Southern Hemisphere winter stratosphere. J. Atmos. Sci., 70, 2120-2136, doi:10.1175/JAS-D-12-0238.1.

,-- , and I.-S. Song, 2009: Gravity wave temperature variance calculated using the ray-based spectral parameterization of convective gravity waves and its comparison with Microwave Limb Sounder observations. J. Geophys. Res., 114 D08111, doi:10.1029/2008JD011330.

— _ _ J J. Gong, and D. L. Wu, 2012: Comparison of gravity wave temperature variances from ray-based spectral param- eterization of convective gravity wave drag with AIRS observations. J. Geophys. Res., 117, D05115, doi:10.1029/ 2011JD016900.

Chun, H.-Y., and J.-J. Baik, 1998: Momentum flux by thermally induced internal gravity waves and its approximation for large-scale models. J. Atmos. Sci., 55, 3299-3310, doi:10.1175/ 1520-0469(1998)055<3299:MFBTII >2.0.CO;2.

- H.-J. Choi, and I.-S. Song, 2008: Effects of nonlinearity on convectively forced internal gravity waves: Application to a gravity wave drag parameterization. J. Atmos. Sci., 65, 557575, doi:10.1175/2007JAS2255.1.

de la Cámara, A., F. Lott, and A. Hertzog, 2014: Intermittency in a stochastic parameterization of nonorographic gravity waves. J. Geophys. Res. Atmos., 119, 11905-11919, doi:10.1002/ 2014JD022002.

Dhaka, S. K., and Coauthors, 2010: Influence of large-scale variations in convective available potential energy (CAPE) and solar cycle over temperature in the tropopause region at Delhi $\left(28.3^{\circ} \mathrm{N}, 77.1^{\circ} \mathrm{E}\right)$, Kolkata $\left(22.3^{\circ} \mathrm{N}, 88.2^{\circ} \mathrm{E}\right)$, Cochin $\left(10^{\circ} \mathrm{N}, 77^{\circ} \mathrm{E}\right)$, and Trivandrum $\left(8.5^{\circ} \mathrm{N}, 77.0^{\circ} \mathrm{E}\right)$ using radiosonde during 1980-2005. Earth Planets Space, 62, 319-331, doi:10.5047/eps.2009.09.001.

Dunkerton, T. J., 1997: The role of gravity waves in the quasibiennial oscillation. J. Geophys. Res., 102, 26053-26076, doi:10.1029/96JD02999.

English, S. J., R. J. Renshaw, P. C. Dibben, A. J. Smith, P. J. Rayer, C. Poulsen, F. W. Saunders, and J. E. Eyre, 2000: A comparison of the impact of TOVS and ATOVS satellite sounding data on the accuracy of numerical weather forecasts. Quart. J. Roy. Meteor. Soc., 126, 2911-2931, doi:10.1002/qj.49712656915.

Ern, M., and P. Preusse, 2012: Gravity wave momentum flux spectra observed from satellite in the summertime subtropics: Implications for global modeling. Geophys. Res. Lett., 39, L15810, doi:10.1029/2012GL052659.

_, _ , J. C. Gille, C. L. Hepplewhite, M. G. Mlynczak, J. M. Russell III, and M. Riese, 2011: Implications for atmospheric dynamics derived from global observations of gravity wave momentum flux in stratosphere and mesosphere. J. Geophys. Res., 116, D19107, doi:10.1029/2011JD015821.

_ L L. Hoffmann, and P. Preusse, 2017: Directional gravity wave momentum fluxes in the stratosphere derived from highresolution AIRS temperature data. Geophys. Res. Lett., 44, 475-485, doi:10.1002/2016GL072007.

Fritts, D. C., and M. J. Alexander, 2003: Gravity wave dynamics and effects in the middle atmosphere. Rev. Geophys., 41, 1003, doi:10.1029/2001RG000106.

_ evidence of a saturated gravity wave spectrum in the troposphere and lower stratosphere. J. Atmos. Sci., 45, 1741-1759, doi:10.1175/1520-0469(1988)045<1741:OEOASG > 2.0.CO;2.

Garcia, R. R., T. J. Dunkerton, R. S. Lieberman, and R. A. Vincent, 1997: Climatology of the semiannual oscillation of the tropical middle atmosphere. J. Geophys. Res., 102, 26 019-26 032, doi:10.1029/97JD00207.

Geller, M. A., T. Zhou, and P. T. Love, 2015: Tropical gravity wave momentum fluxes and latent heating distributions. J. Atmos. Sci., 72, 2762-2768, doi:10.1175/JAS-D-15-0020.1.

Gille, J., and Coauthors, 2008: High Resolution Dynamics Limb Sounder: Experiment overview, recovery, and validation of initial temperature data. J. Geophys. Res., 113, D16S43, doi:10.1029/2007JD008824.

Hertzog, A., G. Boccara, R. A. Vincent, and F. Vial, 2008: Estimation of gravity wave momentum flux and phase speeds from 
quasi-Lagrangian stratospheric balloon flights. Part II: Results from the Vorcore campaign in Antarctica. J. Atmos. Sci., 65, 3056-3070, doi:10.1175/2008JAS2710.1.

—, M. J. Alexander, and R. Plougonven, 2012: On the intermittency of gravity wave momentum flux in the stratosphere. J. Atmos. Sci., 69, 3433-3448, doi:10.1175/ JAS-D-12-09.1.

Hoffmann, L., X. Xue, and M. J. Alexander, 2013: A global view of stratospheric gravity wave hotspots located with Atmospheric Infrared Sounder observations. J. Geophys. Res. Atmos., 118, 416-434, doi:10.1029/2012JD018658.

Hong, S.-Y., and H.-L. Pan, 1996: Nonlocal boundary layer vertical diffusion in a medium-range forecast model. Mon. Wea. Rev., 124, 2322-2339, doi:10.1175/1520-0493(1996)124<2322: NBLVDI $>2.0 . C O ; 2$.

Jewtoukoff, V., R. Plougonven, and A. Hertzog, 2013: Gravity waves generated by deep tropical convection: Estimates from balloon observations and mesoscale simulations. J. Geophys. Res. Atmos., 118, 9690-9707, doi:10.1002/jgrd.50781.

— A. Hertzog, R. Plougonven, A. de la Cámara, and F. Lott, 2015: Comparison of gravity waves in the Southern Hemisphere derived from balloon observations and the ECMWF analyses. J. Atmos. Sci., 72, 3449-3468, doi:10.1175/JAS-D-14-0324.1.

Kalisch, S., H.-Y. Chun, M. Ern, P. Preusse, Q. T. Trinh, S. D. Eckermann, and M. Riese, 2016: Comparison of simulated and observed convective gravity waves. J. Geophys. Res. Atmos., 121, 13 474-13 492, doi:10.1002/2016JD025235.

Khaykin, S. M., A. Hauchecorne, N. Mzé, and P. Keckhut, 2015: Seasonal variation of gravity wave activity at midlatitudes from 7 years of COSMIC GPS and Rayleigh lidar temperature observations. Geophys. Res. Lett., 42, 1251-1258, doi:10.1002/ 2014GL062891.

Kim, J.-E., and M. J. Alexander, 2013: Tropical precipitation variability and convectively coupled equatorial waves on submonthly time scales in reanalysis and TRMM. J. Climate, 26, 3013-3030, doi:10.1175/JCLI-D-12-00353.1.

Kim, Y.-H., and H.-Y. Chun, 2015: Contributions of equatorial wave modes and parameterized gravity waves to the tropical QBO in HadGEM2. J. Geophys. Res. Atmos., 120, 1065-1090, doi:10.1002/2014JD022174.

— A. C. Bushell, D. R. Jackson, and H.-Y. Chun, 2013: Impacts of introducing a convective gravity-wave parameterization upon the QBO in the Met Office Unified Model. Geophys. Res. Lett., 40, 1873-1877, doi:10.1002/grl.50353.

Lane, T. P., M. J. Reeder, and T. L. Clark, 2001: Numerical modeling of gravity wave generation by deep tropical convection. J. Atmos. Sci., 58, 1249-1274, doi:10.1175/1520-0469(2001) $058<1249$ :NMOGWG $>2.0 . \mathrm{CO} ; 2$.

Liess, S., and M. A. Geller, 2012: On the relationship between QBO and distribution of tropical deep convection. J. Geophys. Res., 117, D03108, doi:10.1029/2011JD016317.

Lin, Y.-L., and R. B. Smith, 1986: Transient dynamics of airflow near a local heat source. J. Atmos. Sci., 43, 40-49, doi:10.1175/ 1520-0469(1986)043<0040:TDOANA > 2.0.CO;2.

— , and H.-Y. Chun, 1991: Effects of diabatic cooling in a shear flow with a critical level. J. Atmos. Sci., 48, 2476-2491, doi:10.1175/1520-0469(1991)048<2476:EODCIA > 2.0.CO;2.

Lindzen, R. S., 1981: Turbulence and stress owing to gravity wave and tidal breakdown. J. Geophys. Res., 86, 9707-9714, doi:10.1029/JC086iC10p09707.

Liu, H.-L., J. M. McInerney, S. Santos, P. H. Lauritzen, M. A. Taylor, and N. M. Pedatella, 2014: Gravity waves simulated by high-resolution Whole Atmosphere Community
Climate Model. Geophys. Res. Lett., 41, 9106-9112, doi:10.1002/2014GL062468.

Mantua, N. J., and S. R. Hare, 2002: The Pacific decadal oscillation. J. Oceanogr., 58, 35-44, doi:10.1023/A:1015820616384.

Matsuno, T., 1982: A quasi one-dimensional model of the middle atmosphere circulation interacting with internal gravity waves. J. Meteor. Soc. Japan, 60, 215-226, doi:10.2151/ jmsj1965.60.1_215.

Newman, M., and Coauthors, 2016: The Pacific decadal oscillation, revisited. J. Climate, 29, 4399-4427, doi:10.1175/JCLI-D-15-0508.1.

Newton, C. W., 2004: Associations between twice-yearly oscillations of the North Pacific cyclone track and uppertropospheric circulations over the Eastern Hemisphere. Mon. Wea. Rev., 132, 348-367, doi:10.1175/1520-0493(2004) $132<0348$ :ABTOOT $>2.0 . C O ; 2$.

Pan, H., and W.-S. Wu, 1995: Implementing a mass flux convective parameterization package for the NMC medium range forecast model. National Meteorological Center Office Note 409, 43 pp. [Available online at http://www.ncep.noaa.gov/ officenotes/NOAA-NPM-NCEPON-0005/01408A42.pdf.]

Preusse, P., M. Ern, P. Bechtold, S. D. Eckermann, S. Kalisch, Q. T. Trinh, and M. Riese, 2014: Characteristics of gravity waves resolved by ECMWF. Atmos. Chem. Phys., 14, 10 483-10 508, doi:10.5194/acp-14-10483-2014.

Richter, J. H., A. Solomon, and J. T. Bacmeister, 2014: On the simulation of the quasi-biennial oscillation in the Community Atmosphere Model, version 5. J. Geophys. Res. Atmos., 119, 3045-3062, doi:10.1002/2013JD021122.

Roy Bhowmik, S. K., S. Sen Roy, and P. K. Kundu, 2008: Analysis of large-scale conditions associated with convection over the Indian monsoon region. Int. J. Climatol., 28, 797-821, doi:10.1002/joc. 1567.

Saha, S., and Coauthors, 2010: NCEP Climate Forecast System Reanalysis. Bull. Amer. Meteor. Soc., 91, 1015-1057, doi:10.1175/2010BAMS3001.1.

Salby, M. L., and R. R. Garcia, 1987: Transient response to localized episodic heating in the tropics. Part I: Excitation and short-time near-field behavior. J. Atmos. Sci., 44, 458-498, doi:10.1175/1520-0469(1987)044<0458:TRTLEH>2.0.CO;2.

Sato, K., C. Tsuchiya, M. J. Alexander, and L. Hoffmann, 2016: Climatology and ENSO-related interannual variability of gravity waves in the Southern Hemisphere subtropical stratosphere revealed by high-resolution AIRS observations. J. Geophys. Res. Atmos., 121, 7622-7640, doi:10.1002/ 2015JD024462.

Schirber, S., E. Manzini, and M. J. Alexander, 2014: A convectionbased gravity wave parameterization in a general circulation model: Implementation and improvements on the QBO. J. $A d v$. Model. Earth Syst., 6, 264-279, doi:10.1002/2013MS000286.

Smith, R. B., 1979: The influence of mountains on the atmosphere. Advances in Geophysics, Vol. 21, Academic Press, 87-230.

_ and Y.-L. Lin, 1982: The addition of heat to a stratified airstream with application to the dynamics of orographic rain. Quart. J. Roy. Meteor. Soc., 108, 353-378, doi:10.1002/ qj. 49710845605 .

Song, I.-S., and H.-Y. Chun, 2005: Momentum flux spectrum of convectively forced internal gravity waves and its application to gravity wave drag parameterization. Part I: Theory. J. Atmos. Sci., 62, 107-124, doi:10.1175/JAS-3363.1.

,-- , and T. P. Lane, 2003: Generation mechanisms of convectively forced internal gravity waves and their propagation to the stratosphere. J. Atmos. Sci., 60, 1960-1980, doi:10.1175/ 1520-0469(2003)060<1960:GMOCFI >2.0.CO;2. 
, R. R. Garcia, and B. A. Boville, 2007: Momentum flux spectrum of convectively forced internal gravity waves and its application to gravity wave drag parameterization. Part II: Impacts in a GCM (WACCM). J. Atmos. Sci., 64, 2286-2308, doi:10.1175/JAS3954.1.

Stephan, C., M. J. Alexander, and J. H. Richter, 2016: Characteristics of gravity waves from convection and implications for their parameterization in global circulation models. J. Atmos. Sci., 73, 2729-2742, doi:10.1175/JAS-D-15-0303.1.

Trinh, Q. T., S. Kalisch, P. Preusse, M. Ern, H.-Y. Chun, S. D. Eckermann, M.-J. Kang, and M. Riese, 2016: Tuning of a convective gravity wave source scheme based on HIRDLS observations. Atmos. Chem. Phys., 16, 7335-7356, doi:10.5194/ acp-16-7335-2016.

Tsuchiya, C., K. Sato, M. J. Alexander, and L. Hoffmann, 2016 MJO-related intraseasonal variation of gravity waves in the Southern Hemisphere tropical stratosphere revealed by highresolution AIRS observations. J. Geophys. Res. Atmos., 121, 7641-7651, doi:10.1002/2015JD024463.

Tsuda, T., M. Nishida, C. Rocken, and R. H. Ware, 2000: A global morphology of gravity wave activity in the stratosphere revealed by the GPS occultation data (GPS/MET). J. Geophys. Res., 105, 7257-7273, doi:10.1029/1999JD901005.

VanZandt, T. E., 1982: A universal spectrum of buoyancy waves in the atmosphere. Geophys. Res. Lett., 9, 575-578, doi:10.1029/ GL009i005p00575.

Wang, J., W. Wang, X. Fu, and K.-H. Seo, 2012: Tropical intraseasonal variability in the CFSR. Climate Dyn., 38, 2191-2207, doi:10.1007/s00382-011-1087-0.

Wang, W., P. Xie, S.-H. Yoo, Y. Xue, A. Kumar, and X. Wu, 2011: An assessment of the surface climate in the NCEP Climate
Forecast System Reanalysis. Climate Dyn., 37, 1601-1620, doi:10.1007/s00382-010-0935-7.

Watanabe, S., Y. Kawatani, Y. Tomikawa, K. Miyazaki, M. Takahashi, and K. Sato, 2008: General aspects of a T213L256 middle atmosphere general circulation model. J. Geophys. Res., 113, D12110, doi:10.1029/2008JD010026.

Wei, J., F. Zhang, and J. H. Richter, 2016: An analysis of gravity wave spectral characteristics in moist baroclinic jet-front systems. J. Atmos. Sci., 73, 3133-3155, doi:10.1175/ JAS-D-15-0316.1.

Wilks, D. S., 2006: Statistical Methods in the Atmospheric Sciences. Academic Press, 676 pp.

Wright, C. J., and J. C. Gille, 2011: HIRDLS observations of gravity wave momentum fluxes over the monsoon regions. J. Geophys. Res., 116, D12103, doi:10.1029/2011JD015725.

, S. M. Osprey, and J. C. Gille, 2013: Global observations of gravity wave intermittency and its impact on the observed momentum flux morphology. J. Geophys. Res. Atmos., 118, 10 980-10 993, doi:10.1002/jgrd.50869.

,-- , and -2015 : Global distributions of overlapping gravity waves in HIRDLS data. Atmos. Chem. Phys., 15, 84598477, doi:10.5194/acp-15-8459-2015.

Yan, X., N. Arnold, and J. Remedios, 2010: Global observations of gravity waves from High Resolution Dynamics Limb Sounder temperature measurements: A yearlong record of temperature amplitude and vertical wavelength. J. Geophys. Res., 115, D10113, doi:10.1029/2008JD011511.

Zhang, L., A. Kumar, and W. Wang, 2012: Influence of changes in observations on precipitation: A case study for the Climate Forecast System Reanalysis (CFSR). J. Geophys. Res., 117, D08105, doi:10.1029/2011JD017347. 